\section{Contrast-enhanced ultrasonography for the evaluation of malignant focal liver lesions}

\author{
Maria Cristina Chammas, André Leopoldino Bordini \\ Department of Radiology, Hospital das Clínicas, School of Medicine, University of São Paulo, \\ São Paulo, Brazil
}

In this review, the authors address the analysis of different types of malignant focal liver lesions (FLLS) using contrast-enhanced ultrasonography (CEUS). The specific enhancing patterns of hepatocellular carcinoma, cholangiocarcinoma, and metastases are discussed and exemplified with images. In addition, the use of CEUS in malignant portal vein thrombosis is discussed. The advantages and limitations of CEUS for the analysis of malignant FLLs are also discussed.

Keywords: Contrast-enhanced ultrasound; Liver neoplasms; Focal liver lesions; Contrast media; Ultrasonography

Key points: During the contrast-enhanced ultrasonography, malignant focal liver lesions typically show washout. Early/marked washout is typical of metastasis and late-mild washout most likely indicates hepatocellular carcinoma. Contrast-enhanced ultrasonography can distinguish bland from malignant portal vein thrombi.

\section{Introduction}

Contrast-enhanced ultrasonography (CEUS) is an imaging modality in which a microbubble contrast agent is intravenously injected, allowing the characterization of real-time enhancement patterns in focal liver lesions (FLLs), similarly to contrast-enhanced computed tomography (CT) and contrastenhanced magnetic resonance imaging (MRI). Real-time imaging provided by CEUS also has advantages, including the detection of very early or transient arterial enhancement that may be missed in other methods such as CT and MRI. In addition, it is important to highlight that CEUS has virtually no known adverse effects, may be used in patients with impaired renal function, and does not use ionizing radiation $[1,2]$. CEUS has also been shown to be a more cost-effective imaging modality than CT and MRI [1,3-8].

Regarding malignant hepatic lesions, CEUS plays an important role in the detection of metastases, with an accuracy similar to that of CT [1,9-11]. It also has good sensitivity and specificity in the evaluation of malignant lesions, such as hepatocellular carcinoma (HCC), intrahepatic cholangiocellular carcinoma (ICC), and malignant portal vein thrombosis [10,12-14].

The purpose of this paper is to review the assessment of malignant liver lesions using CEUS, considering the specific imaging characteristics of each type of lesion, and the circumstances in which

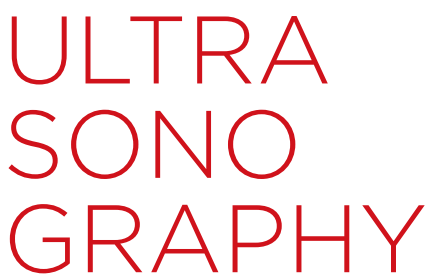

\section{REVIEW ARTICLE}

https://doi.org/10.14366/usg.21001 pISSN: 2288-5919 • elSSN: 2288-5943

Ultrasonography 2022;41:4-24

Received: January 1, 2021

Revised: August 17, 2021

Accepted: August 17, 2021

Correspondence to:

Maria Cristina Chammas, MD, PhD, Ultrasound Division, Department of Radiology, Hospital das Clínicas, University of São Paulo, Av. Dr. Enéas de Carvalho Aguiar, $s / n^{\circ}$, Cerqueira Cesar ZIP 01246903, São Paulo, SP, Brazil

Tel. +55-(11)-2661-6478

Fax. +55-(11)-2661-6478

E-mail: mcchammas@hotmail.com, cristina.chammas@hc.fm.usp.br

This is an Open Access article distributed under the terms of the Creative Commons Attribution NonCommercial License (http://creativecommons.org/ licenses/by-nc/4.0/) which permits unrestricted noncommercial use, distribution, and reproduction in any medium, provided the original work is properly cited.

Copyright @ 2022 Korean Society of Ultrasound in Medicine (KSUM)

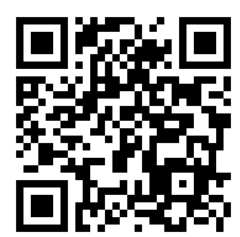

How to cite this article:

Chammas MC, Bordini AL. Contrast-enhanced ultrasonography for the evaluation of malignant focal liver lesions. Ultrasonography. 2022 Jan;41(1):4-24. 
CEUS is the imaging modality of choice.

\section{Principles, Techniques, and Concepts of CEUS}

\section{Types of Contrast Media}

Various contrast agents are available worldwide. Sulfur hexafluoride microbubbles (SonoVue, Bracco, Milan, Italy) are the most commonly used, being available in many countries worldwide. Perflutren lipid microspheres (Definity, Lantheus Medical Imaging, North Billerica, MA, USA), and perfluorobutane microbubbles (Sonazoid, GE Healthcare, Oslo, Norway) are also used; the latter is mainly used in Asia, and has high persistence in the liver, being specific for the hepatic parenchyma Kupffer phase [2].

SonoVue, the most widely used contrast agent, is composed of sulfur hexafluoride microbubbles surrounded by a phospholipid shell. After mixing with saline, a microbubble suspension is obtained, which is then injected into a peripheral vein as a bolus (generally $2.4 \mathrm{~mL}$, using a 20-gauge catheter and a three-way stopcock), in a direction close to parallel to the vessel, followed by a saline injection $(10 \mathrm{~mL})$. At the time of injection, images should start to be recorded, and a timer should be started for later evaluation and documentation. Sonazoid has similar principles and behavior as SonoVue, but it is also phagocytized by Kupffer cells, persisting for several hours in the liver and spleen after its vascular phase, allowing a "post-vascular phase" [1,2]. The ultrasonography (US) equipment has a dedicated mode that allows the cancelation of tissue signals and the formation of microbubble signals. This is accomplished by using low acoustic pressure (low mechanical index), minimizing bubble disruption $[1,2,15]$.

\section{Considerations prior to CEUS}

Clinical information and patient history are taken into consideration when interpreting imaging data. The main issues regarding clinical features are as follows: Is the lesion incidental in a healthy patient or is the FLL part of a clinical presentation (such as cancer, infectious diseases, or chronic liver disease)? What is the patient's current clinical presentation (fever, nutritional status, blood work findings)? What previous liver treatments has the patient received (such as chemoembolization, radiofrequency ablation, or percutaneous ethanol ablation)? Does the patient have risk factors for HCC (such as a history of chronic liver disease, cirrhosis, hepatitis, exposure to hepatotoxic compounds, alcohol consumption, and metabolic syndrome) and for liver metastases (i.e., known extrahepatic malignancy, previous chemotherapy/radiotherapy)? Access to prior exams for comparison (laboratory data and any prior imaging findings) is also mandatory when performing CEUS.

Evaluations using CEUS should always include B-mode US and
Doppler US assessments prior to contrast injection. This allows the operator to gather information regarding liver morphology, the location of focal lesions, and also to be aware of the best acoustic windows and patient positions ideal for analysis. In addition, nonvascular findings such as cysts and calcifications must be identified prior to contrast injection because they might be misinterpreted as hypovascular or malignant lesions in post-contrast phases [1].

\section{Phases and Features of Malignancy Detected by CEUS}

CEUS allows real-time evaluation of multiple intravascular phases over several minutes, greatly increasing US accuracy. Indeed, realtime evaluation is an advantage of CEUS, when compared to CT and MRI, especially with regard to its sensitivity in detecting very rapid arterial enhancement. However, the short duration of arterial enhancement makes the simultaneous assessment of multiple lesions impracticable. Experienced operators and adequate technique are mandatory.

Even though the exam occurs in real-time, it may be divided into three vascular phases and a post-vascular phase (Table 1). The phases of liver CEUS include the arterial phase, which starts $10-20$ seconds and ends $30-45$ seconds after contrast injection and provides information on the degree and pattern of the arterial vascular supply of an FLL. The portal venous phase, which lasts from 30-45 seconds to 2 minutes after contrast agent injection, is characterized by diffuse and maximal enhancement of the normal liver parenchyma. The late phase lasts until the clearance of the contrast agent from circulation (usually from 4 to 6 minutes after the contrast injection). Finally, the post-vascular phase is only observed with Sonazoid and reflects the uptake of the contrast agent by phagocytic cells (e.g., Kupffer cells). It starts 8 minutes after the contrast agent injection and may last for several minutes or even hours. CEUS enables the vascular architecture and phase-specific contrast enhancement of the lesion to be seen as compared to the adjacent liver parenchyma. These are the most important diagnostic features for the characterization of FLLs [16-18].

An important characteristic of microbubble contrast agents is that

Table 1. Vascular and post-vascular phases in contrast-enhanced ultrasonography of the liver (visualization post-injection time)

\begin{tabular}{lcc}
\hline \multicolumn{1}{c}{ Phase } & Start (s) & End (s) \\
\hline Arterial & $10-20$ & $30-45$ \\
Portal venous & $30-45$ & 120 \\
Late & $>120$ & Bubble disappearance (approx. 4-8 min) \\
Post-vascular & $>480$ & Approx. 30 min \\
\hline
\end{tabular}

Based on Guidelines and Good Clinical Practice Recommendations for Contrast Enhanced Ultrasound (CEUS) in the Liver [1]. 
they are confined within the vascular space, with the exception of Sonazoid, while CT and MRI intravenous contrast agents pass over time into the extravascular space. This allows ultrasound contrast agents to persist for several minutes in the liver, providing around 5 minutes of scanning time, which is very important for an analysis of the whole liver, providing good sensitivity for metastasis detection and washed-out lesions.

FLLS are a relatively common finding in healthy patients. CEUS may be the test that leads to the initial identification of an FLL, and it can differentiate benign patterns (such as in hemangiomas) from indeterminate or malignant patterns $[3-6,15,19-33]$, enabling the identification of patients who need further investigation or surgery [33].

It is important to highlight some features that malignant lesions show in different phases of CEUS:

1. Arterial phase hyperenhancement (APHE): This should not be a rim-like or peripheral discontinuous globular pattern. The enhanced portion must be higher in echogenicity than the normal liver in the arterial phase. Echogenicity should be unequivocally greater in the entire FLL or in part of the FLL than in the liver. Generally, APHE is diffuse, although it may be only partially diffuse. Another pattern type is APHE involving contrast with the rim-type, which may also be a characteristic of malignant lesions other than HCC.

2. Washout: Washout is represented by a reduction in enhancement, in whole or in part, of an FLL, relative to the adjacent liver, beginning in or after the arterial phase. This term applies to any observation of enhancement, even in the absence of APHE. Washout can be classified according to onset (early or late) and degree (marked or mild). Onset is the time after injection (in seconds) at which lesion washout is first detected relative to the liver. It can be (1) early: onset detected $<60$ seconds after contrast agent injection; or (2) late: onset detected $\geq 60$ seconds after contrast agent injection. The washout degree is assessed by comparing the nodule-toliver enhancement in the portal venous and late phases. It can be (1) marked, when the nodule is virtually devoid of enhancement ("punched-out") by 2 minutes after contrast agent injection, or (2) mild, when the nodule becomes less enhanced than the liver, but not devoid of enhancement (i.e., some enhancement persists). If this persistent enhancement disappears after 2 minutes, the degree of washout is still considered mild, even if the nodule eventually becomes "punched-out."

Generally, early washout ( $<60$ seconds) is associated with marked washout (a major feature of malignancy) [16], while late washout ( $\geq 60$ seconds) tends to be accompanied by mild washout (more common in HCC). In CEUS, all malignant nodules typically show washout, including ICC and other fibrotic tumors that have delayed central enhancement on CT or MRI [34].

\section{CEUS LI-RADS}

Regarding malignant FLLS, it is important to observe the CEUS Liver Reporting and Data System (LI-RADS) scoring system [16] when applicable, in which eligible patients are classified in categories that range from 1 (definitely benign) to 5 (definitely HCC), according to CEUS characteristics. For example, an FLL is considered definitely HCC (LI-RADS 5) if the lesion shows APHE (not rim nor peripheral discontinuous globular) and has late and mild washout. In addition, there are categories $\mathrm{M}$ (probably or definitively malignant but not HCC-specific) and TIV (definite tumor in vein) (Table 2). For more information, we recommend the use of the CEUS LI-RADS v2017 Core [16] as a reference.

\section{Metastasis}

Metastases are the most common malignant liver lesions and are much more frequent in the clinic than primary liver tumors. In patients with known malignancies, their diagnosis is important for a precise work-up. CEUS greatly increases the sensitivity and specificity of metastasis detection as compared to $\mathrm{CT}$ and MRI for lesions with a diameter less than or equal to $1 \mathrm{~cm}[9-11]$.

It is possible to differentiate metastases from benign lesions with CEUS. Generally, lesions that show washout in the venous or late phases should be considered suspicious of malignancy [17,35], and most metastases show this characteristic [9-11]. Conventional US has a sensitivity ranging from $50 \%$ to $76 \%$ for detecting liver metastases, whereas, according to a meta-analysis including 828 metastases from 18 studies, the overall sensitivity of CEUS for diagnosis of metastases is $91 \%$ (95\% confidence interval $[\mathrm{Cl}], 87 \%$

Table 2. Simplified American College of Radiology CEUS LI-RADS diagnostic table

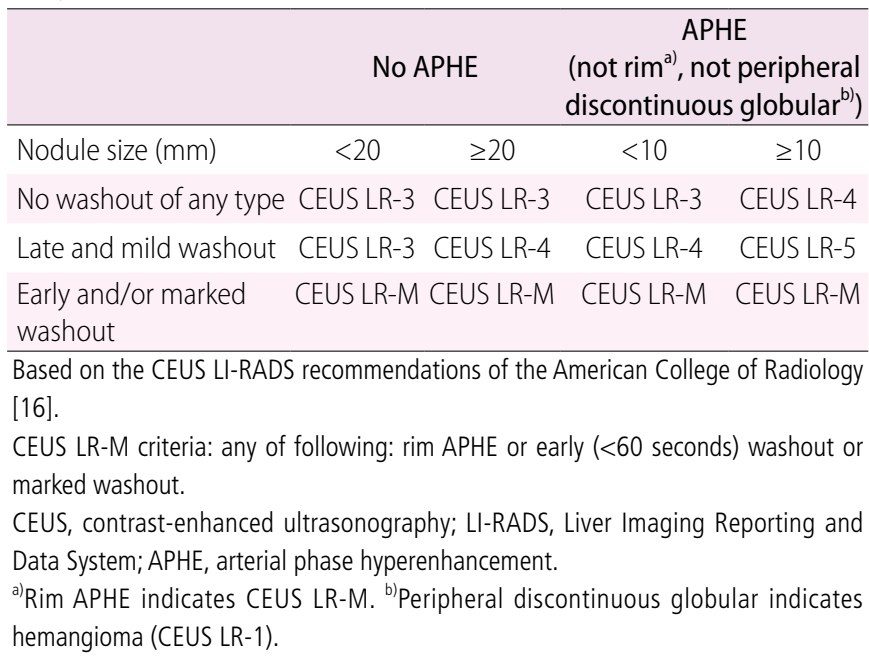


to $95 \%$ ) [8]. As mentioned before, US contrast agents persist for several minutes in the liver, providing sufficient time to scan the whole liver and good sensitivity for metastasis detection.

The imaging characteristics of CEUS are similar to those of contrast-enhanced $\mathrm{CT}$ and MRI, mainly enabling the detection of hypovascular lesions. During the arterial phase of CEUS imaging, metastases may present tenuous and peripheral enhancement. This occurs due to the preponderant arterial supply to these lesions. In later phases, metastases are hypoechoic in relation to the surrounding parenchyma, which greatly enhances their detection.
This may occur due to the lower portal supply to these lesions or the lower blood volume of metastases, as compared to that of the normal liver parenchyma [11].

The major criteria for characterization of metastases by CEUS are as follows:

Rim APHE: This refers to a spatially-defined subtype of APHE, in which the arterial phase enhancement is most pronounced in the nodule periphery, forming a contrast halo around it (Fig. 1)

Early washout ( $<60$ seconds): Early washout is a temporally defined subtype of washout, in which the onset occurs within 60

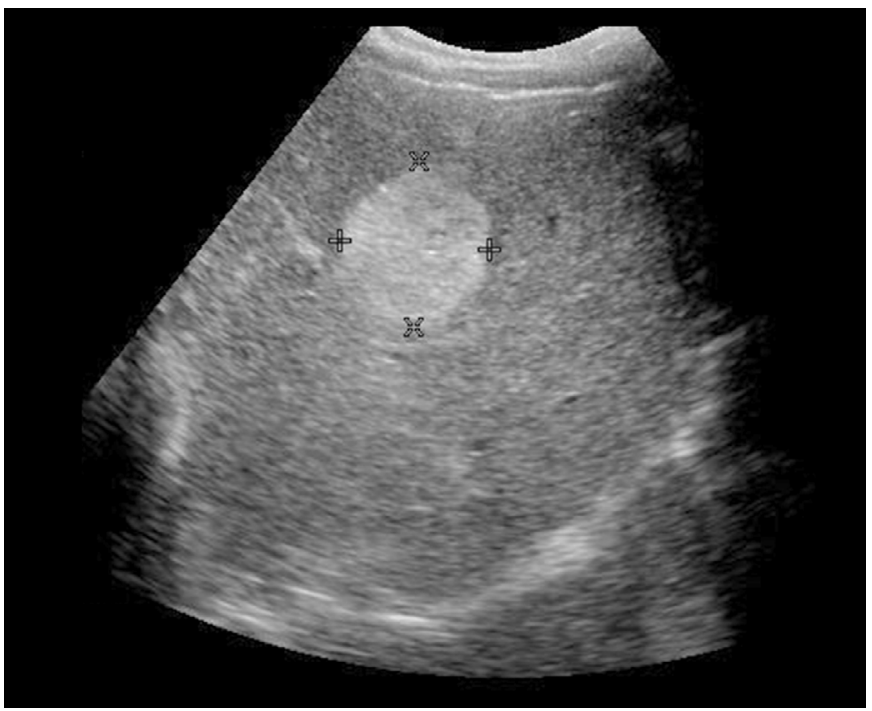

A

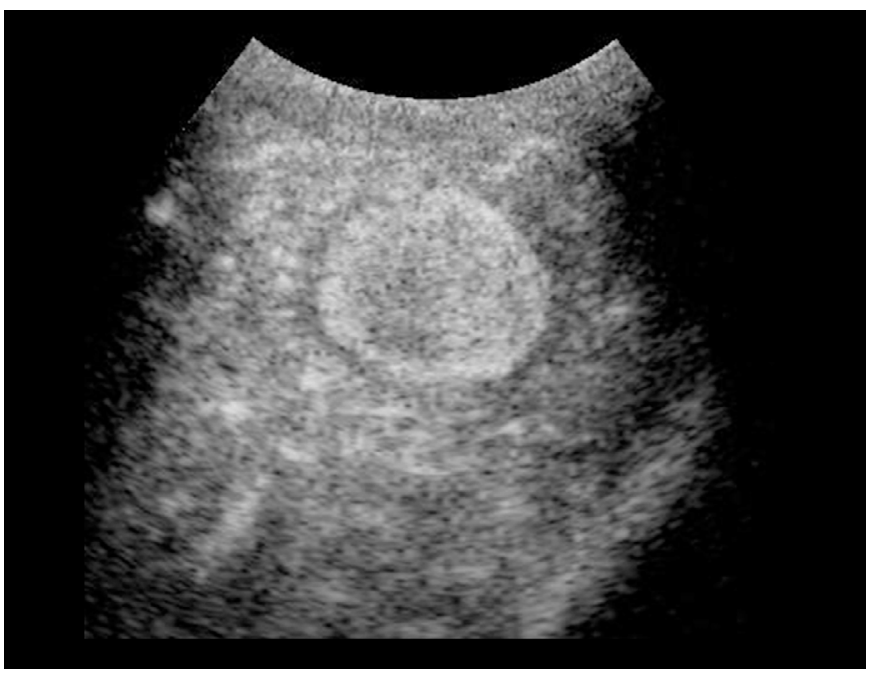

C

Fig. 1. Metastasis of neuroendocrine tumor in a 65-year-old man.

A. Pre-contrast phase shows hyperechoic nodule by B-mode ultrasonography, measuring $3.6 \times 3.2 \mathrm{~cm}$ in segment VIII. B-D. After the injection of the contrast agent (B), rim-type arterial hyperenhancement and early washout (less 1 minute) are demonstrated during the portal (C) and late phase (D).

e-ultrasonography.org

Ultrasonography 41(1), January 2022 
seconds after contrast injection. It is also usually marked in degree (Fig. 2).

Marked washout: This category denotes a degree-defined subtype of washout, in which there is marked washout within 2 minutes after contrast injection. The metastases appear black or punched out (Figs. 3, 4).

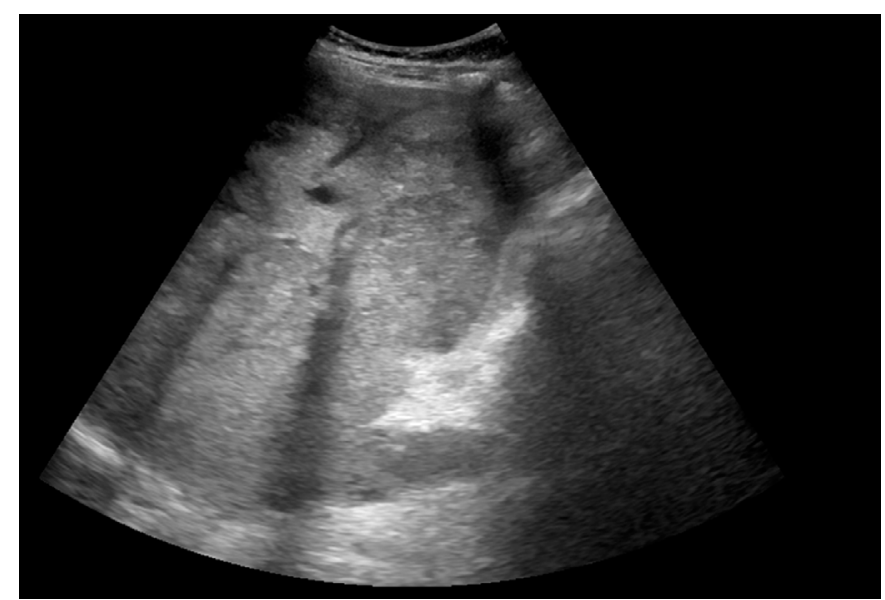

A

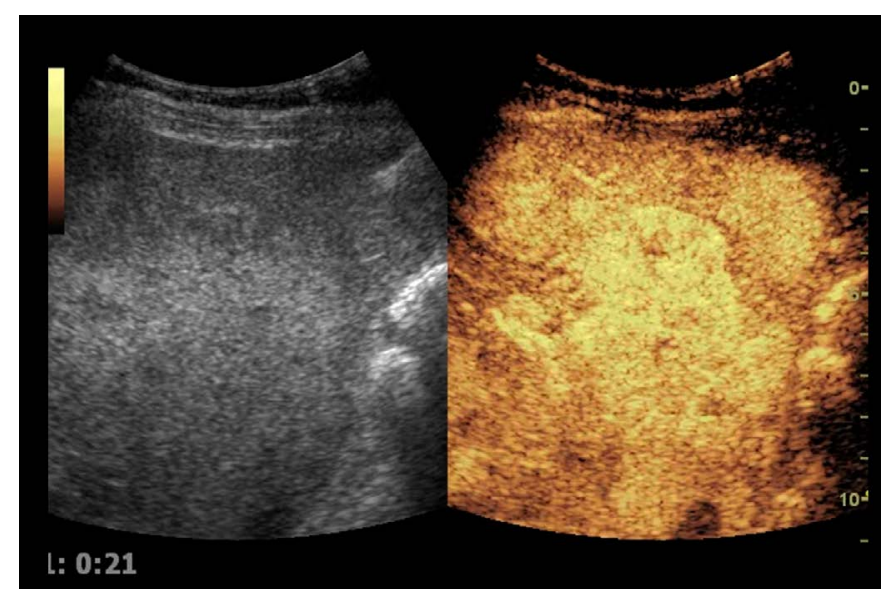

C

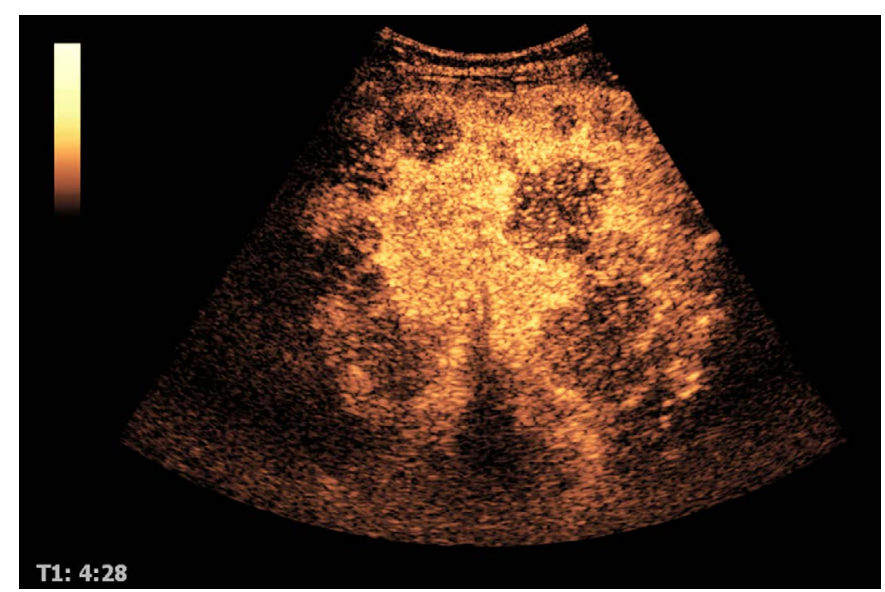

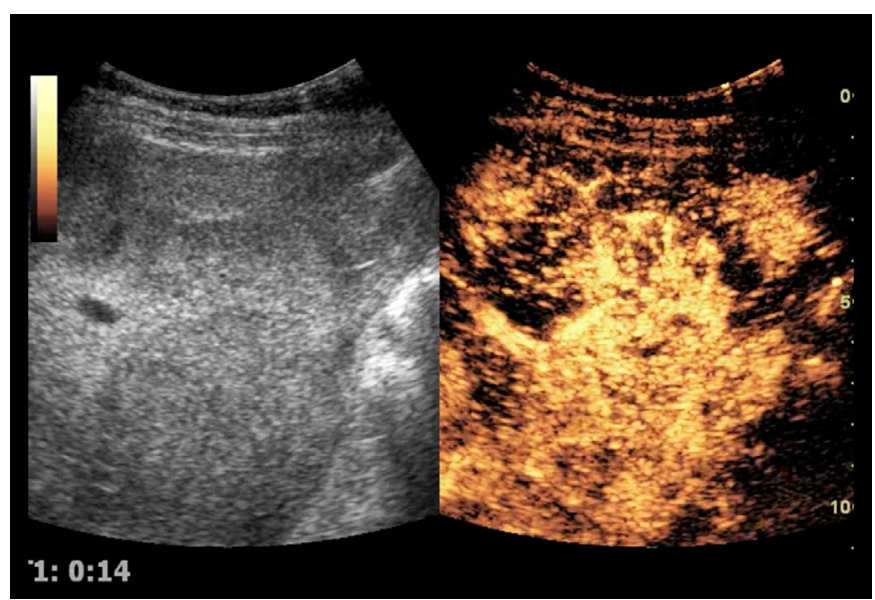

B

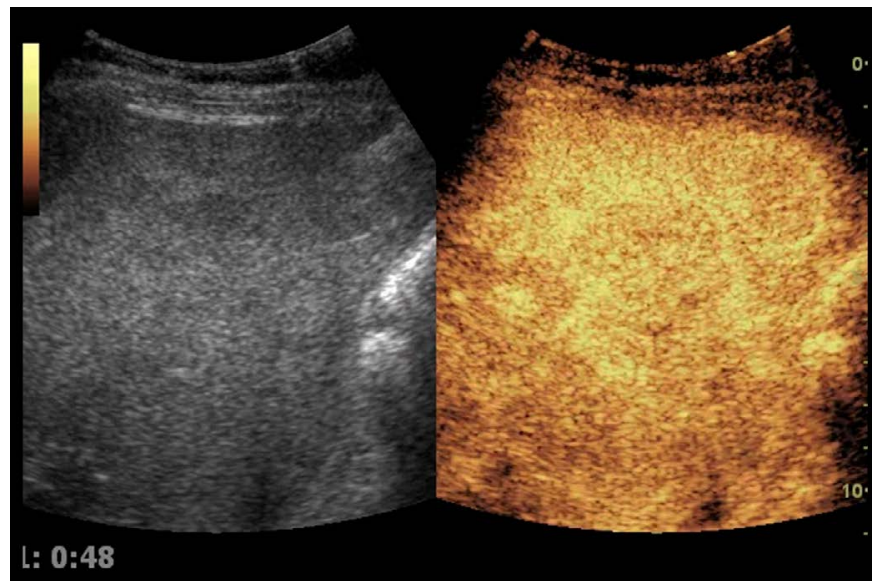

D

Fig. 2. Metastasis of rectal adenocarcinoma in a 55-year-old man showing ill-defined B-mode isoechoic nodules, distributed in the liver parenchyma.

A. Pre-contrast-enhanced ultrasonography is shown. B-E. After the injection of contrast agent, 0.14 minutes, 0.21 minutes, 0.48 minutes and 4.28 minutes post contrast injection), several nodules (and additional nodules) are observed with arterial hyperenhancement and rapid washout (portal and late phase). $B, C$. Early arterial phase (14 seconds and 21 seconds) shows hyperenhancement that starts in nodule periphery and progresses to total highlighting of the nodule (C); early washout at 48 seconds, in the portal venous phase, defines better the multiple nodules in the liver parenchima (D); late phase shows intense washout, with best nodules definition (E). 


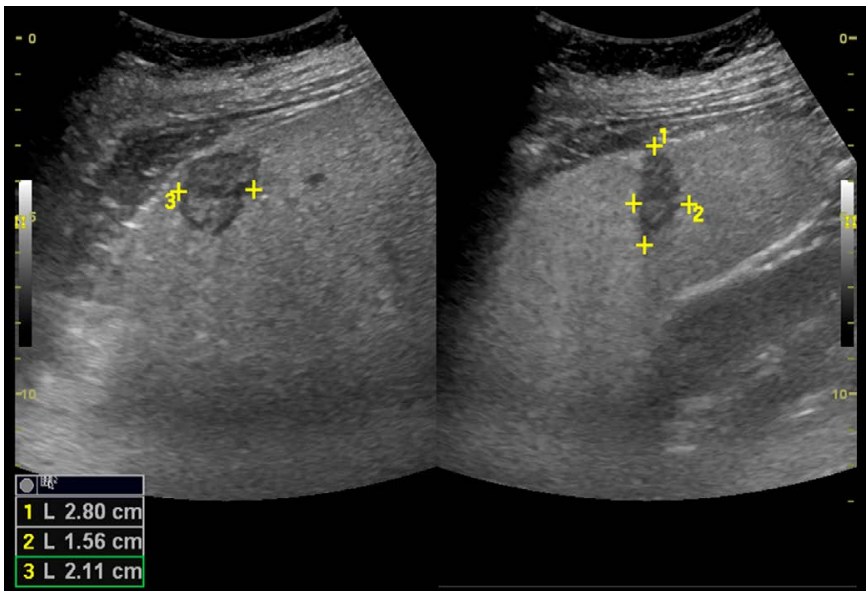

A

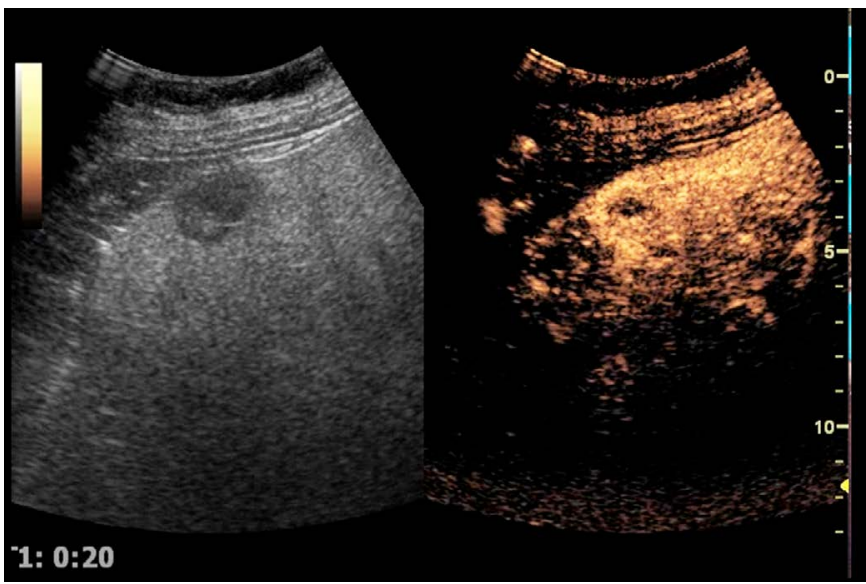

C

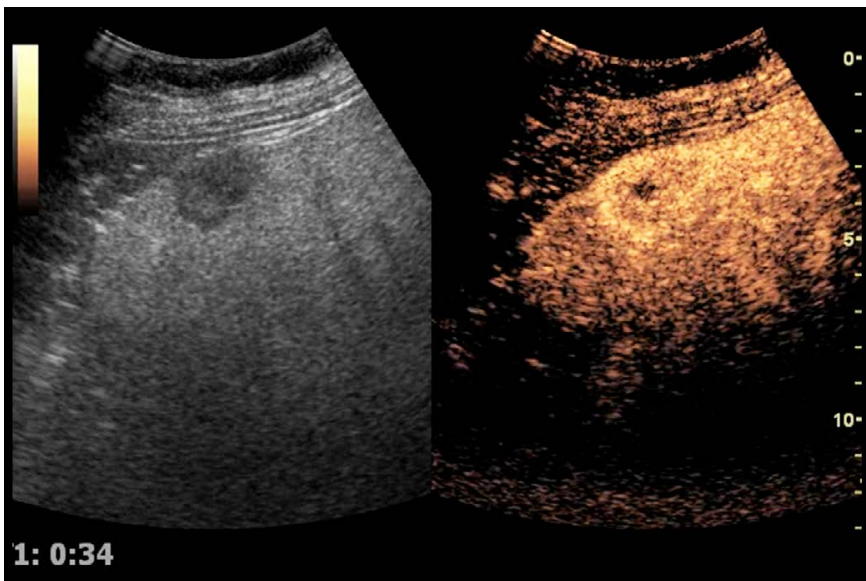

E

Fig. 3. Neuroendocrine pancreatic tumor metastasis in 70-year-old woman.

A. Conventional B-mode ultrasonography pre-contrast-enhanced ultrasonography (CEUS), shows nodule in segment VI, hypoechoic, irregular, measuring about $2.8 \times 2.1 \times 1.5 \mathrm{~cm}$. The CEUS evaluation of the nodule $(B-F)$ shows arterial enhancement $(C, D)$ and early and marked washout in the portal phase (E, F). 
Before contrast injection

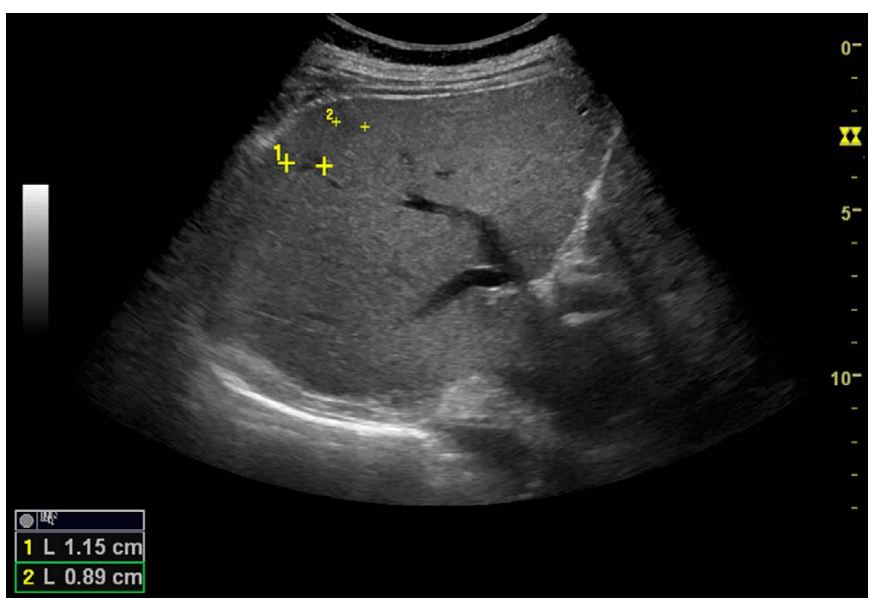

A

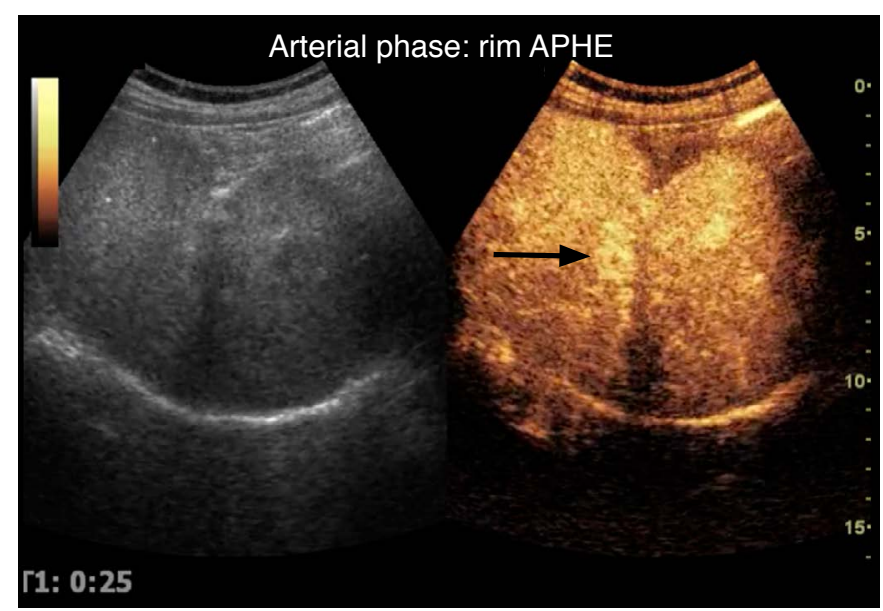

C

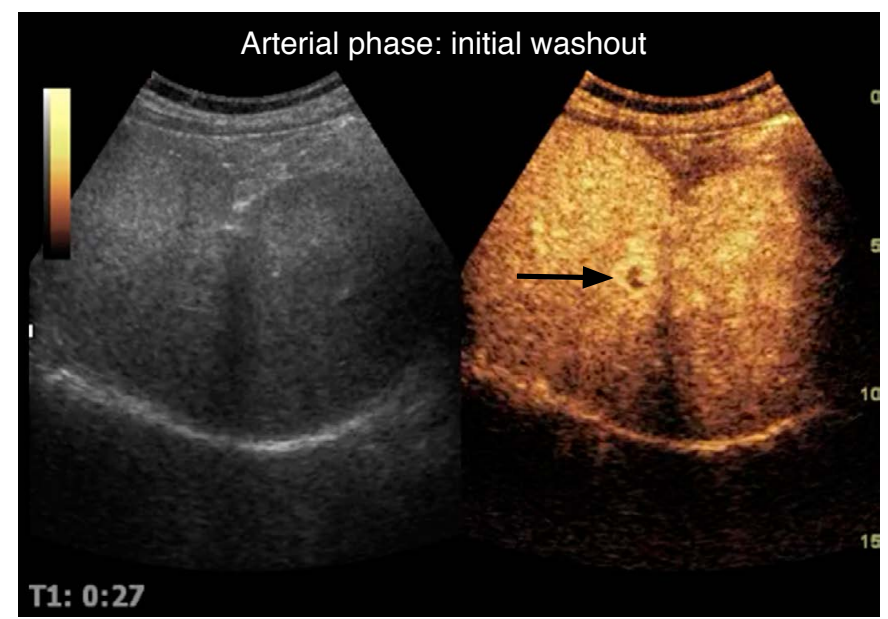

E

Fig. 4. A 52-year-old man with past history of medullary thyroid carcinoma and liver metastasis.

Notice a hypoechoic nodule by B-mode ultrasonography (delimited by calipers in A [axial oblique plane] and B [longitudinal plane]), measuring $1.1 \times 1.1 \times 0.9 \mathrm{~cm}$ in segment VII. After contrast-enhanced ultrasonography, the nodule presents peripheral arterial hyperenhancement (rim arterial phase hyperenhancement, arrow in C), hyperenhancement (D), and early washout (still in the arterial phase, before the portal and late phase) $(E, F)$. The arrows point to the same nodule $(C-F)$ evaluation over time after contrast injection. 


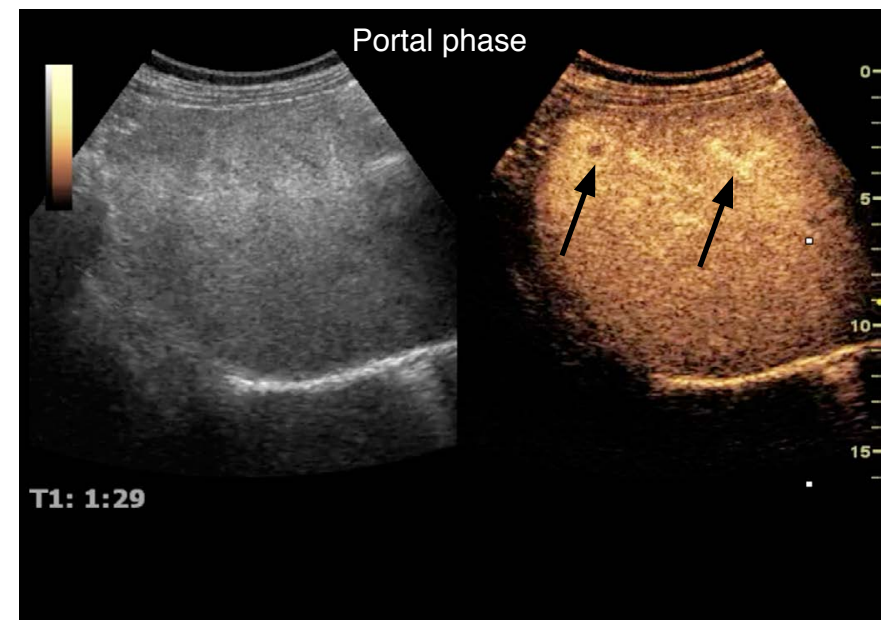

G

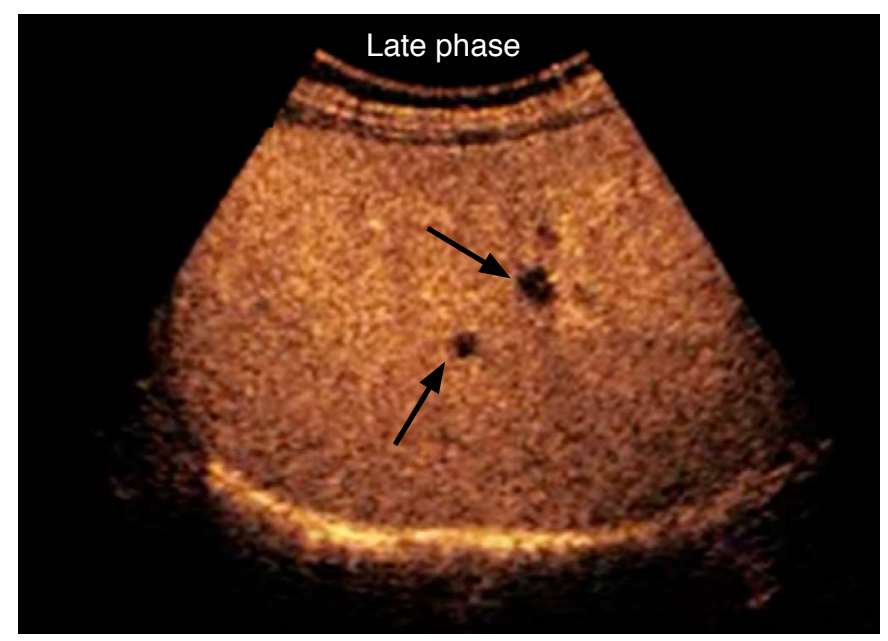

I

\section{Hepatocellular Carcinoma}

HCC is the most common primary liver malignancy in patients with liver cirrhosis (even though they may be unaware of this condition), although the enhancement patterns of HCC are similar regardless of whether the patient has cirrhosis. It is worth mentioning that in the non-cirrhotic liver, HCC tends to be larger at the time of cancer diagnosis and the lesions are usually hyperenhanced in the arterial phase, typically with a chaotic vascular pattern and variable isoenhancement or hypoenhancement in the portal venous and late phases. Hyperenhancement in the arterial phase is often homogeneous, but starts predominantly along the periphery [1].

Conventional US plays an important role in surveillance programs in patients with cirrhosis, allowing the early detection of FLLs, but it is very nonspecific. CEUS increases the specificity of HCC characterization, and increases the sensitivity of FLL diagnosis. A

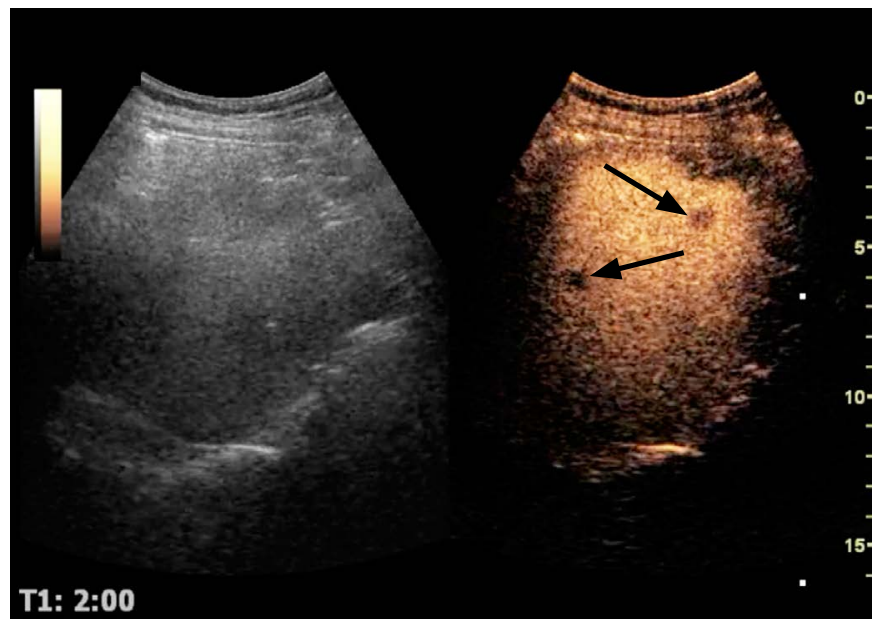

$\mathrm{H}$

Fig. 4. The portal venous phase after CEUS can be seen $(G, H)$ and the late phase is characterized 3.41 minutes after contrast injection (I). With contrast-enhanced ultrasonography, it is possible to identify several small nodules (pointed out with arrows) distributed in the liver with early washout. After the portal phase, it is possible to observe additional nodules not seen in the conventional base ultrasound.

meta-analysis 19 studies with 1,333 HCCs showed a sensitivity of $88 \%(95 \% \mathrm{Cl}, 84 \%$ to $92 \%)$ [8].

Typically, the nodule enhances during the arterial phase and then washes out during the following phases, becoming hypoechoic compared to the rest of the liver. This occurs because the blood supply to the HCC mainly originates from arterial branches.

The key features for the diagnosis of HCC in liver cirrhosis, which are used by the LI-RADS scoring system, are APHE (neither rim-like nor peripheral discontinuous globular), followed by lateonset washout ( $>60$ seconds after injection) and mild washout $[16,34,36-39]$. This pattern of washout in HCC is seen in more than $97 \%$ of cases according to a large retrospective series [40]. Arterial hyperenhancement is usually homogeneous and intense in HCC, but may be heterogeneous in larger nodules $(>5 \mathrm{~cm})$ that are necrotic or have mosaic architecture.

Rim enhancement is atypical for HCC. Washout is observed overall 
in about half of HCC cases, but rarely in small nodules $(20 \%-$ $30 \%$ in those $1-2 \mathrm{~cm}, 40 \%-60 \%$ in those $2-3 \mathrm{~cm}$ ) [41-43]. Washout is observed more frequently in HCCs with poorer grades of differentiation than in well-differentiated HCCs, which tend to be isoenhancing in the late phase [43-46].

Hypoenhancement in the late phase is usually less marked in HCC than in other tumor types $[43,47]$. Furthermore, washout tends to start later in HCCs, usually not before 60 seconds after injection $[43,47]$ and appearing only after 180 seconds in up to $25 \%$ of cases $[43,47]$; consequently, it is important to observe nodules in cirrhotic cases for a long period ( $>4$ minutes) (Figs. 5, 6). Early washout $(<60$ seconds) occurs in poorly differentiated HCC or suggests a nonhepatocellular malignancy $[43,45-47]$, most often an intrahepatic ICC [16].

The use of a low mechanical index is important in order to maintain sufficient signal intensity to allow contrast persistence until the very late phase (beyond 3-4 minutes), which is crucial for detecting washout and establishing a diagnosis of HCC [17].

\section{Intrahepatic Cholangiocellular Carcinoma}

ICC is the second most common primary malignant liver tumor. Unlike its characteristics on CT and MRI, it may show hyperenhancement during the arterial phase of CEUS, and may also show washout in late phases (Figs. 7, 8). It may be difficult to differentiate ICC from HCC.

There is no consensus regarding the differential diagnosis of HCC and ICC by CEUS. Compared to HCC, ICC shows less intense enhancement in the arterial phase and shows early ( $<60$ seconds) and marked washout compared to the typically late and mild washout in HCC [48].

Table 3 shows the role of washout onset and degree in the characterization of malignant FLLs by CEUS [16].

According to CEUS LI-RADS V2017, nodules with late and mild washout may be categorized as CEUS LR-3, LR-4, or LR-5. Nodules with early or marked washout should be categorized as LR-M [16].

Table 4 shows the main enhancement patterns of malignant FLLs.

\section{Malignant Portal Vein Thrombosis}

Malignant portal vein thrombosis occurs due to neoplastic infiltration of the portal vein by tumor cells and is most commonly seen in HCC. It may be difficult to differentiate from non-malignant

Table 3. Washout onset and degree in the characterization of malignant focal liver lesions by CEUS

\begin{tabular}{lll}
\hline \multicolumn{3}{c}{ Washout onset } \\
\hline Washout degree & \multicolumn{1}{c}{ Early $(<60 \mathrm{~s})$} & \multicolumn{1}{c}{ Late $(\geq 60 \mathrm{~s})$} \\
\hline Marked & $\begin{array}{l}\text { Typical of ICC and } \\
\text { metastases }\end{array}$ & $\begin{array}{l}\text { Suggests malignancy in } \\
\text { general, not specific for any } \\
\text { particular type }\end{array}$ \\
Mild & $\begin{array}{l}\text { Suggests malignancy in } \\
\text { general, not specific for any } \\
\text { particular type }\end{array}$ & $\begin{array}{l}\text { Typical of HCC and HCC } \\
\text { precursor nodules }\end{array}$ \\
$\begin{array}{l}\text { Based on the CEUS LI-RADS recommendations of the American College of Radiology } \\
\text { [16]. }\end{array}$ \\
$\begin{array}{l}\text { CEUS, contrast-enhanced ultrasonography; ICC, intrahepatic cholangiocellular } \\
\text { carcinoma; HCC, hepatocellular carcinoma; LI-RADS, Liver Reporting and Data } \\
\text { System. }\end{array}$
\end{tabular}

Table 4. Main enhancement patterns of malignant focal liver lesions

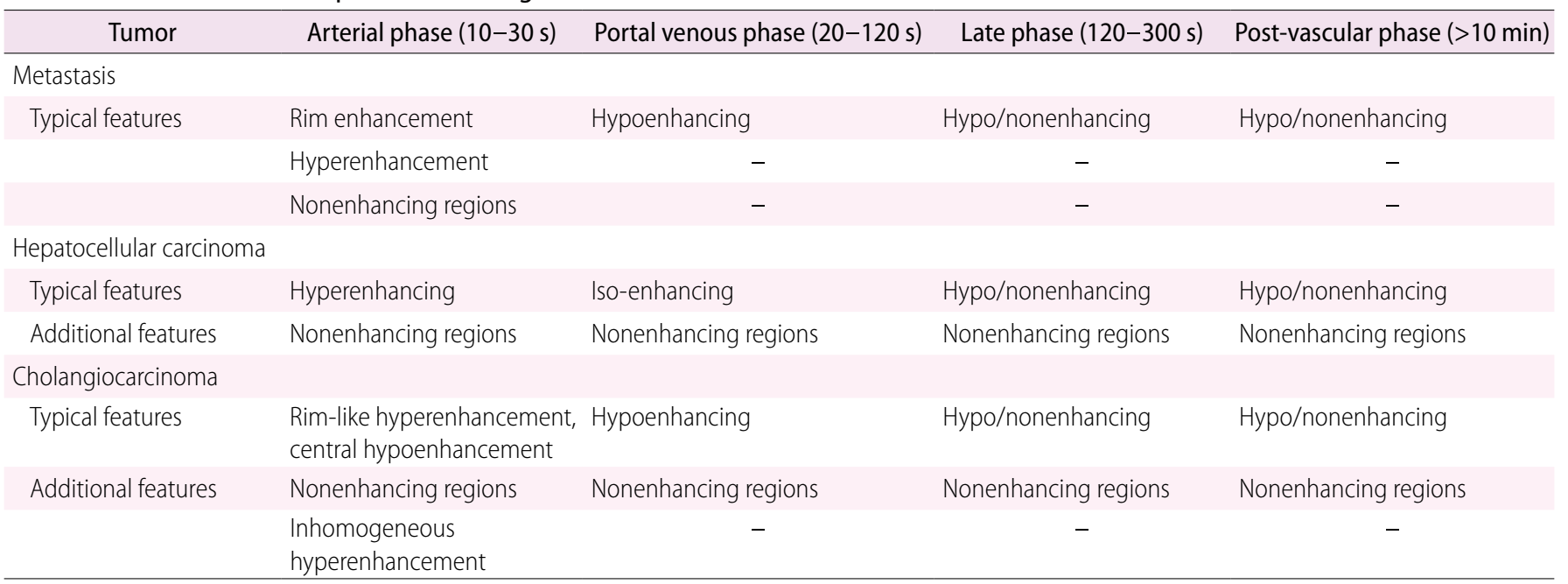

Based on the Guidelines and Good Clinical Practice Recommendations for Contrast Enhanced Ultrasound (CEUS) in the Liver [1]. 


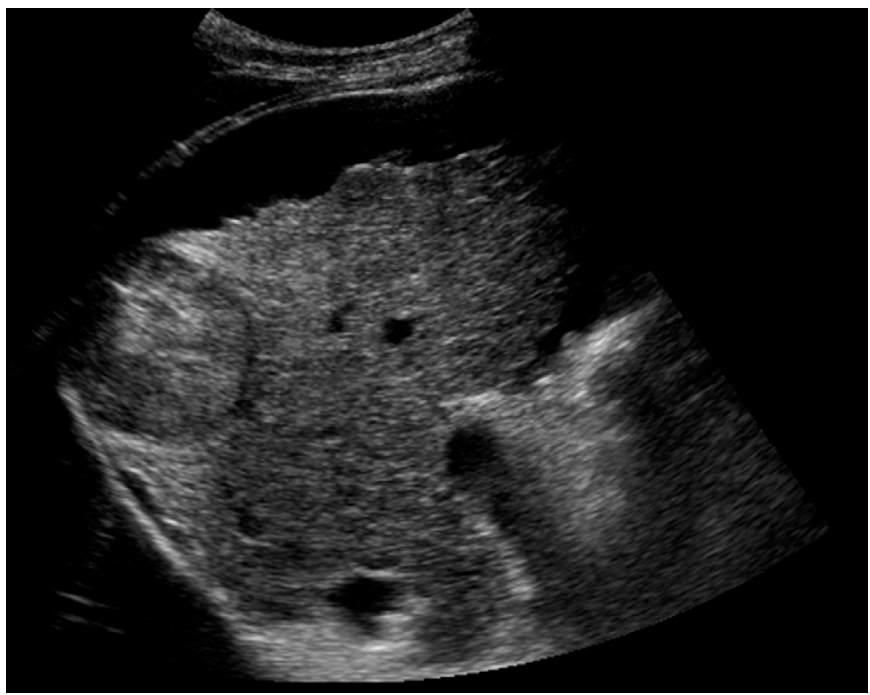

A

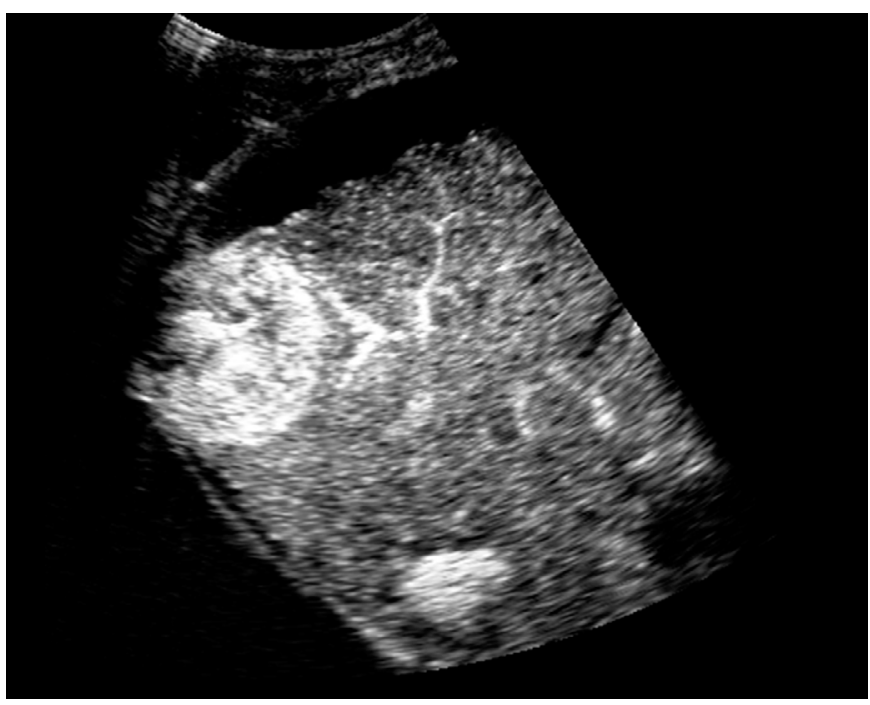

C

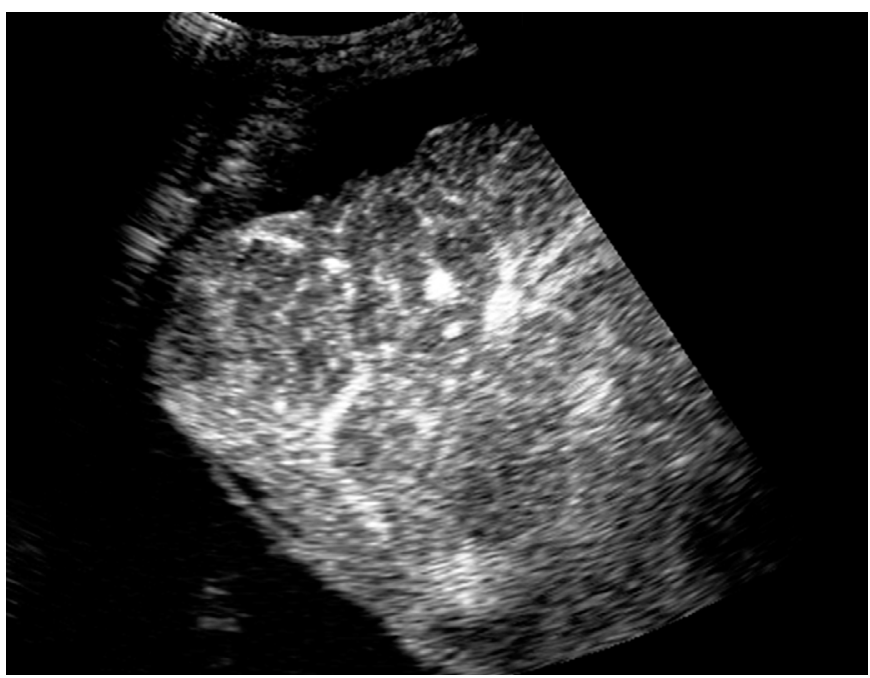

E

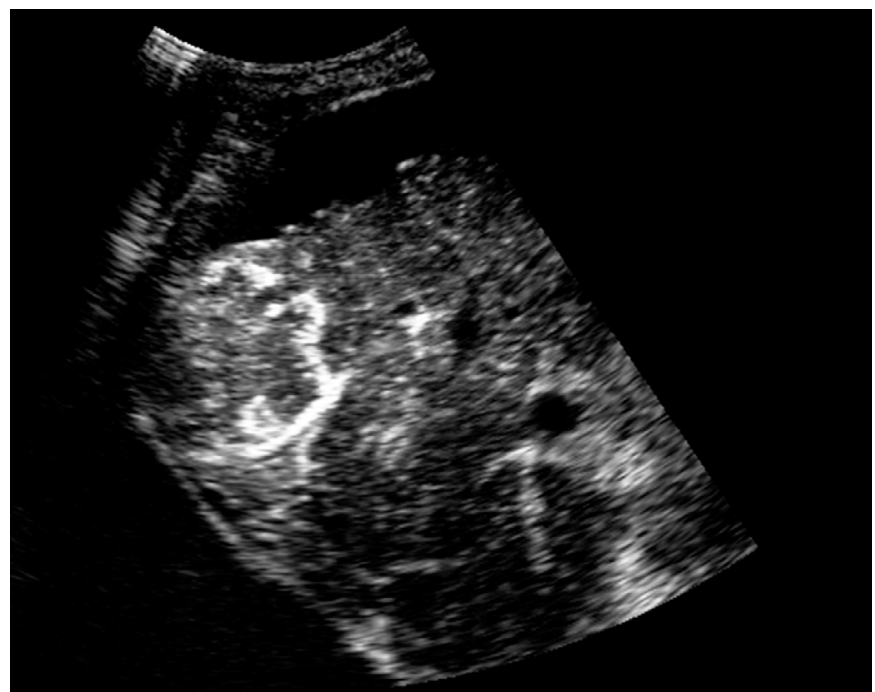

B

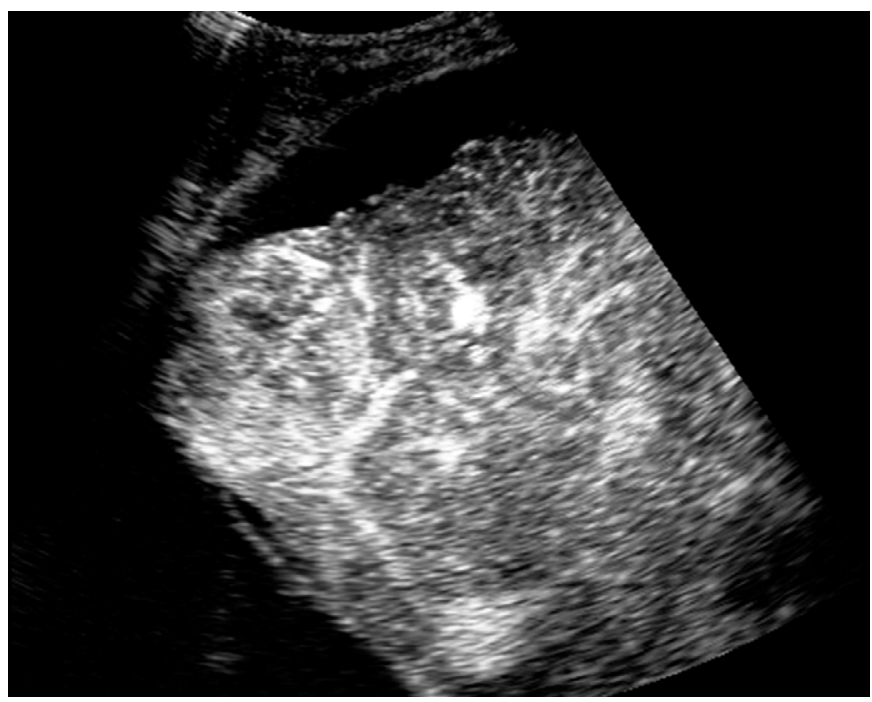

D

Fig. 5. A 67-year-old man with chronic liver disease and hepatocellular carcinoma.

A. B-mode ultrasonography indicates a hypoechoic nodule with well-defined limits. Note the presence of serrated ascites and liver contour. B-E. After contrast agent injection, contrast enhancement starts from the nodule periphery (B) and progresses centripetally (C) during the arterial phase. It is possible to observe a mild washout after 1 minute (D) during the portal venous phase. Mild and late washout (E) is compatible with the CEUS Liver Reporting and Data System 5 (CEUS- LI-RADS 5). 


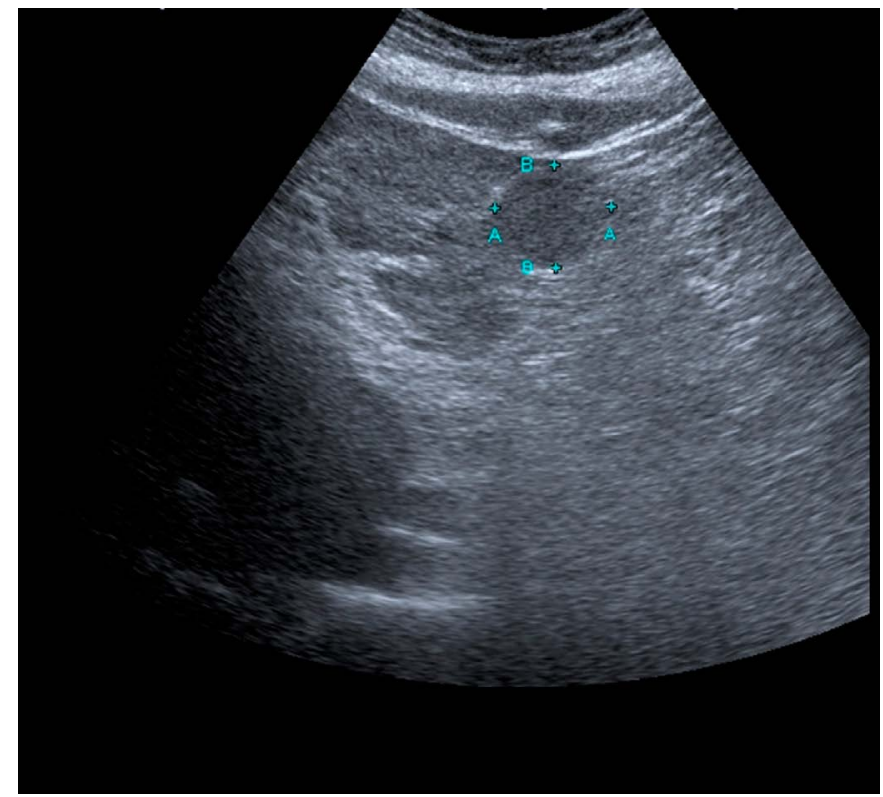

A

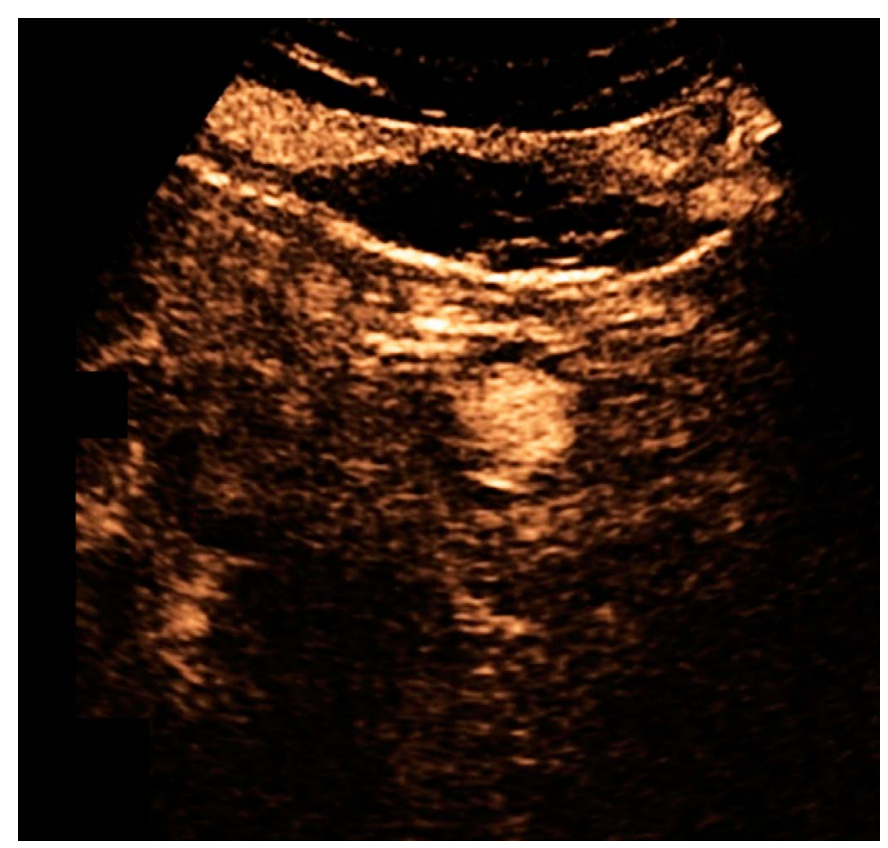

C

Fig. 6. A 53-year-old man with chronic liver disease and hepatocellular carcinoma.

A. B-mode ultrasonography shows a well-defined hypoechoic nodule in the chronic liver disease before contrast-enhanced ultrasonography (CEUS) evaluation. B, C. The arterial phase of CEUS shows nodule enhancement 20 seconds after contrast agent injection. D. In the portal phase, an enhanced nodule appears and, after 1 minute, shows mild washout (mild and late washout). This pattern is compatible with the CEUS Liver Reporting and Data System 5.

(bland) portal vein thrombosis if no intravascular contrast medium is used. The flow inside the thrombi can sometimes be detected by Doppler US, but CEUS provides additional sensitivity in this

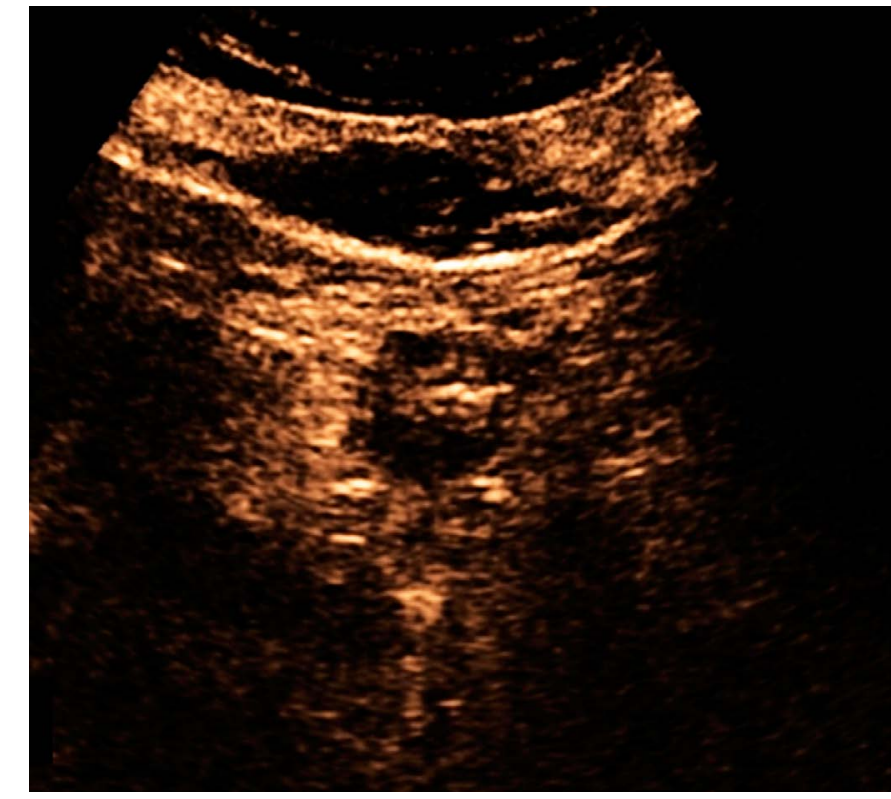

B

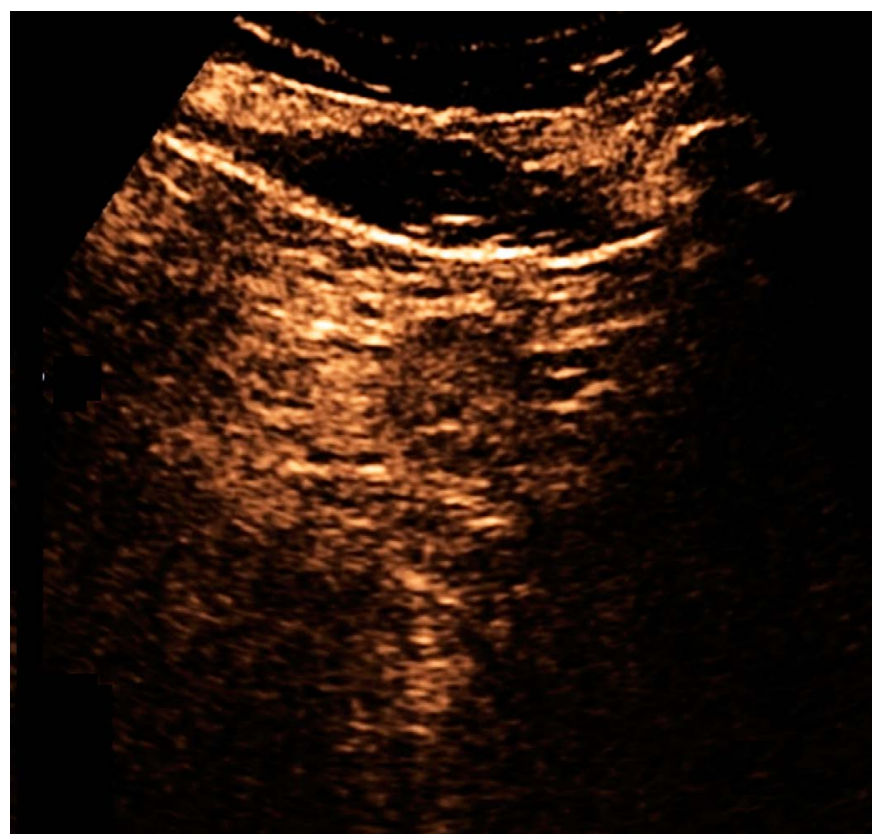

D 


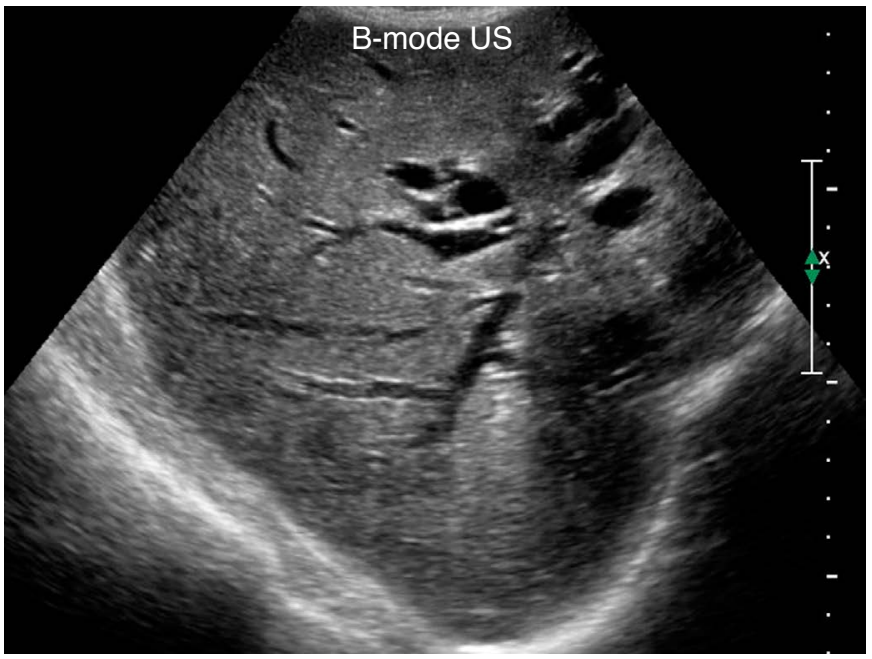

A

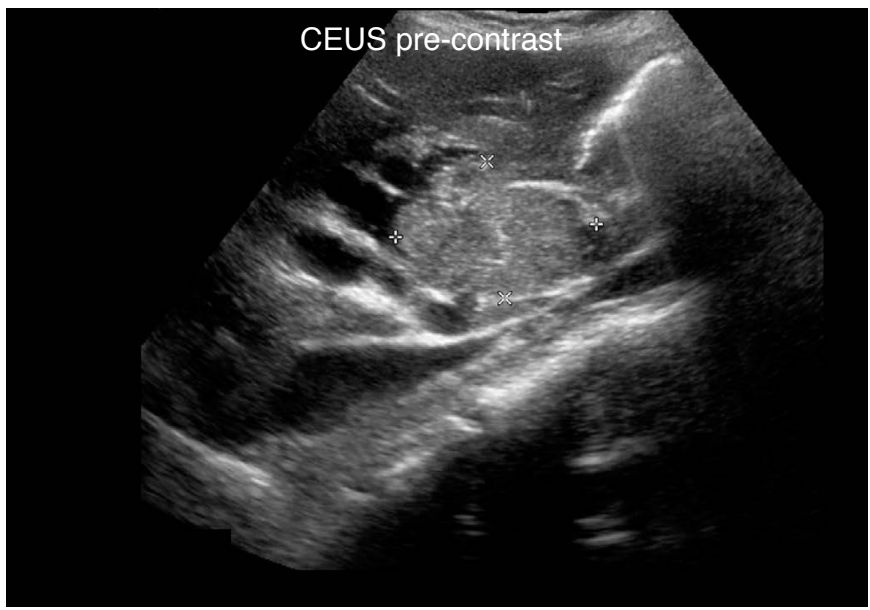

C

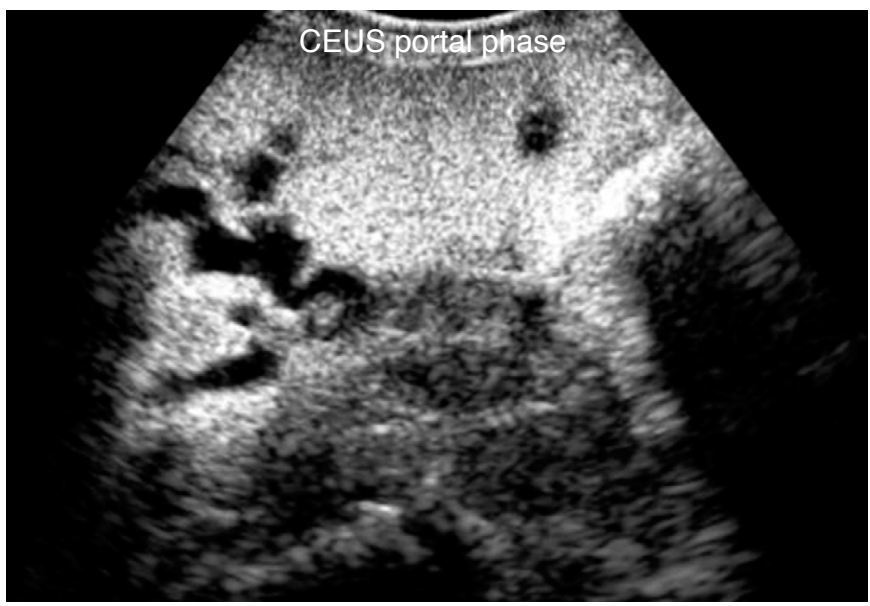

E

Fig. 7. A 63-year-old man, with intrahepatic cholangiocellular carcinoma.

This is an example of Klatskin tumor, central subtype. A. B-mode ultrasonography (US) shows dilated bile ducts, and a "stop" at the level of the hepatic ducts (bifurcation), with a badly defined mass. This is called an invisible tumor in ultrasonography. B. On color Doppler ultrasonography, it is easy to observe the dilated bile ducts versus blood vessels. C-F. Contrast-enhanced ultrasonography (CEUS) evaluation shows a nodule measuring $4.7 \times 3.2 \mathrm{~cm}$, presenting arterial enhancement with early and marked washout, which becomes more pronounced in the late phase. The nodule, measuring $4.7 \times 3.2 \mathrm{~cm}$, shows arterial enhancement with early and marked washout. 


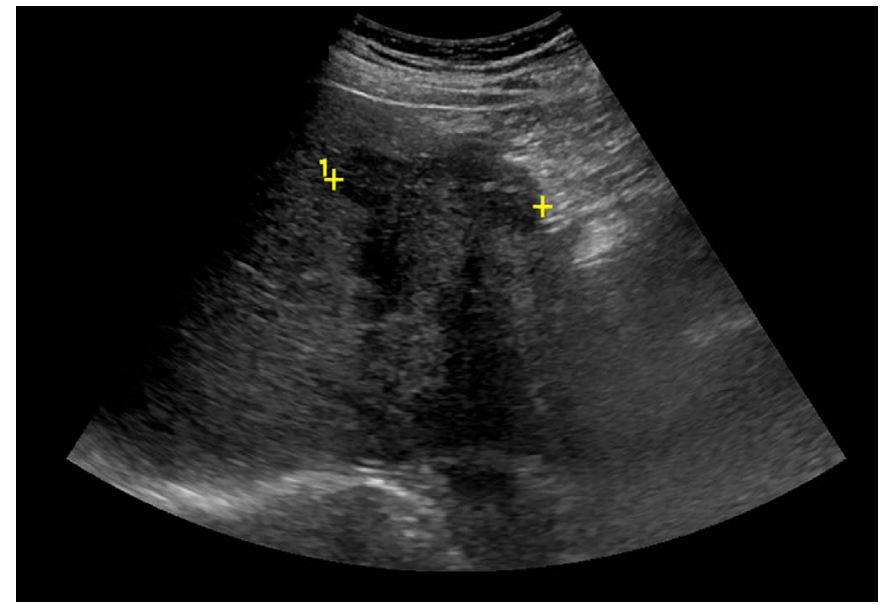

A

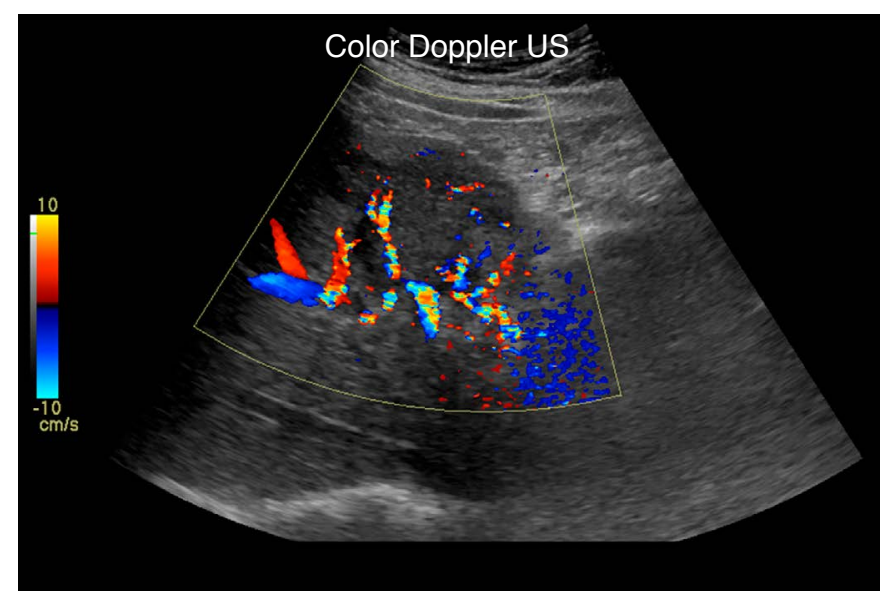

C

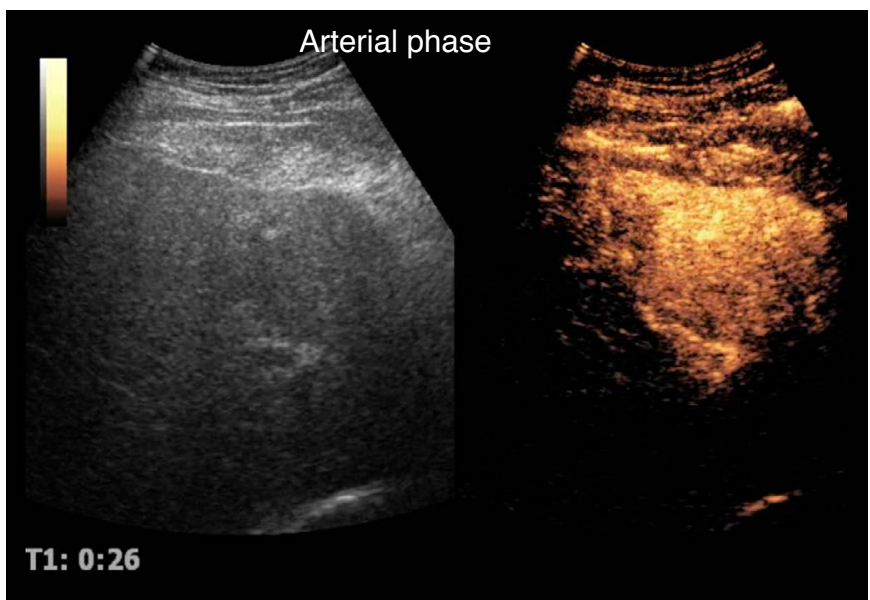

$\mathrm{E}$

Fig. 8. A 56-year-old man, diagnosed with intrahepatic cholangiocellular carcinoma, peripheral subtype.

A, B. B-mode ultrasonography (US) shows an irregular and partially-defined hypoechoic nodule, measuring about $7.6 \times 6.3 \times 5.6 \mathrm{~cm}$, located in segment IV. C. Color Doppler ultrasonography shows predominantly peripheral vascularization. D, E. Arterial phase: After contrastenhanced ultrasonography, arterial enhancement is observed. F-H. Washout starts at 1 minute (F), and marked washout is observed in the portal phase $(G)$, which becomes more pronounced in the late phases $(H)$. 


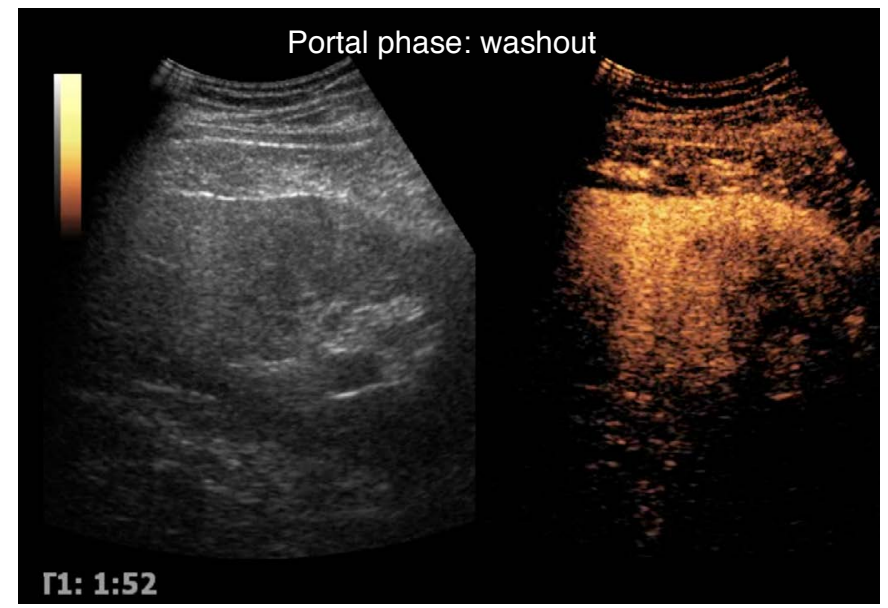

G

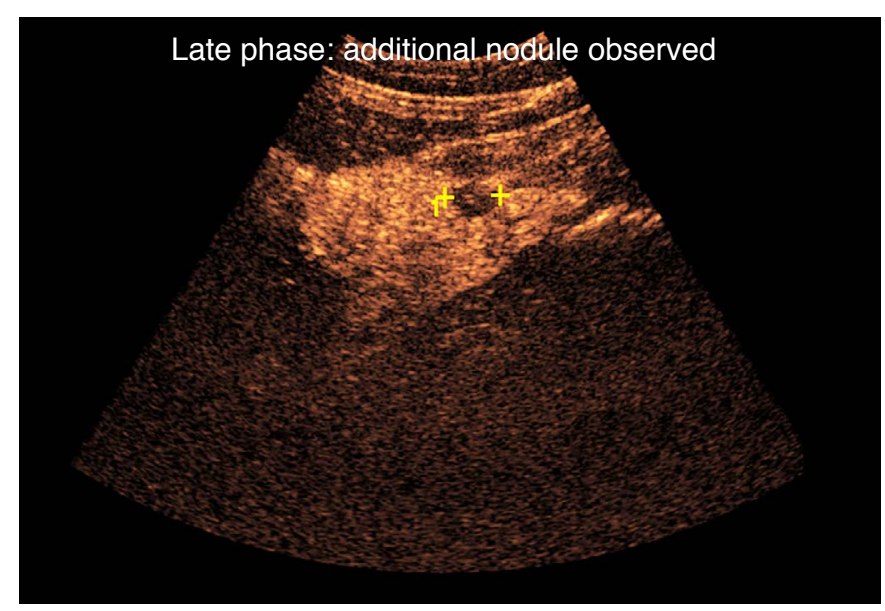

I

void within the enhanced liver in all phases of CEUS, although they are best visualized during the portal venous phase. A "tumor in the vein" (TIV) has the same enhancement characteristics as the tumor from which it originated, including rapid arterial phase hyperenhancement and washout [49-56].

A TIV is considered to be present when unequivocal enhancing soft tissue is found in the vein, regardless of the visualization of a parenchymal mass. The arrival time of the microbubble contrast agent to the vein helps to differentiate TIV from partially occlusive/ recanalized bland thrombi:

- Early arrival (almost at the same time as hepatic artery opacification) favors TIV.

- Arrival several seconds (approximately 10 seconds) after hepatic artery opacification favors portal flow upstream from non-occlusive/ re-canalized bland thrombi [16].

CEUS has been reported to show high sensitivity and specificity ( $90.9 \%$ and $100 \%$, respectively) in detecting malignant portal

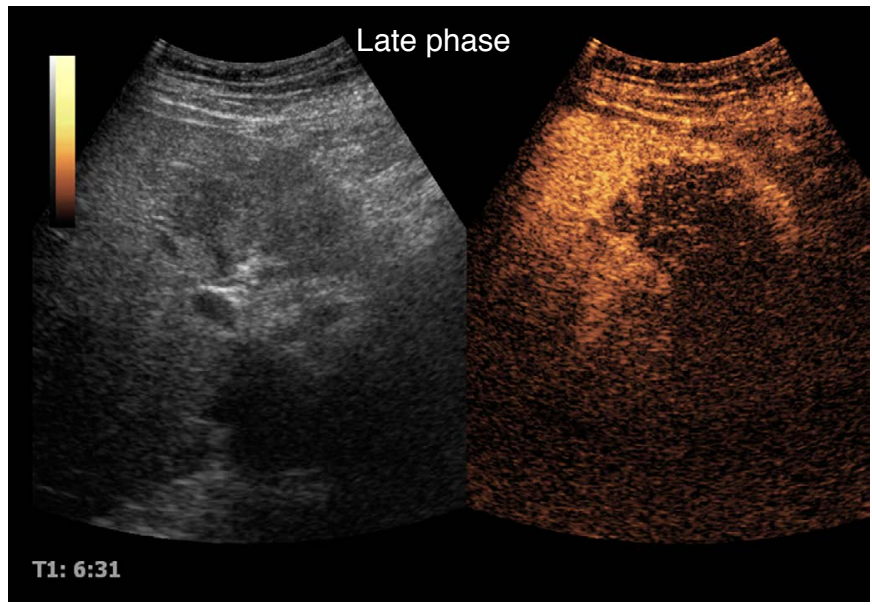

$\mathrm{H}$

Fig. 8. I. It was possible to observe another satellite nodule (surrounded by calipers) in the late phase.

vein thrombosis (PVT) [16]. The reason for this is that CEUS makes the detection of blood flow in the thrombus site easier, which also facilitates spectral Doppler waveform analysis in these cases.

Given that CEUS allows the detection of increased blood flow in PVT, it is possible to differentiate benign and malignant PVT based on both arterial phase enhancement and spectral waveform analysis. Arterial phase enhancement and arterial waveforms are associated with malignant PVT, while portal phase enhancement and venous wave forms occur with benign PVT [49] (Fig. 9).

Blood flow can also be used, with the same reasoning, to assess thrombosis due to tumor invasion of other veins, such as portal vein branches, hepatic veins, and the inferior vena cava, which is important in tumor staging (Fig. 10). CEUS optimizes this evaluation by increasing sensitivity in the detection of arterial flow within veins with thrombi. 


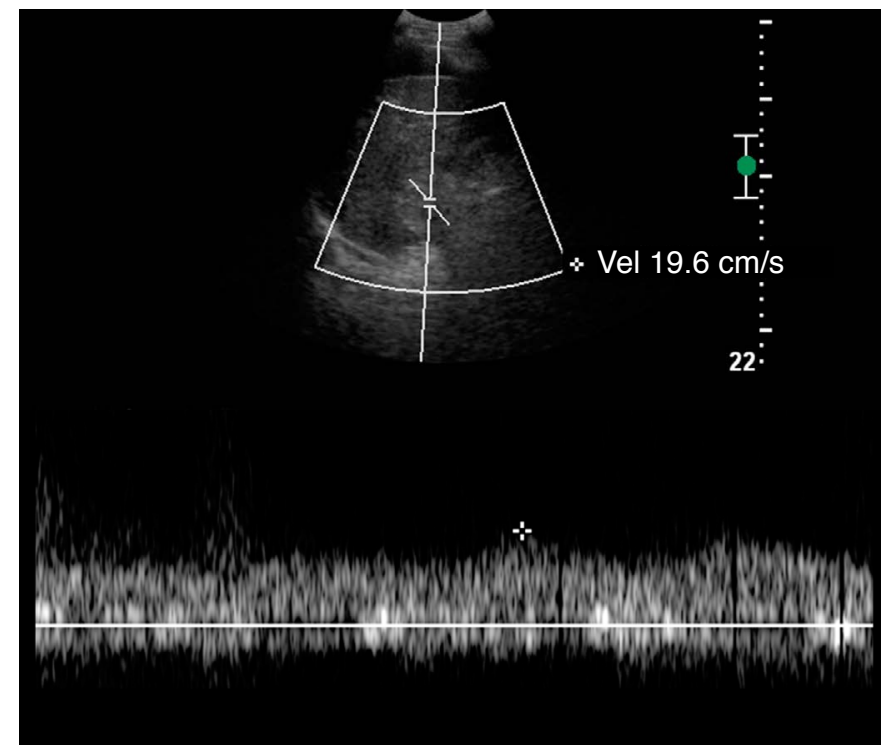

A

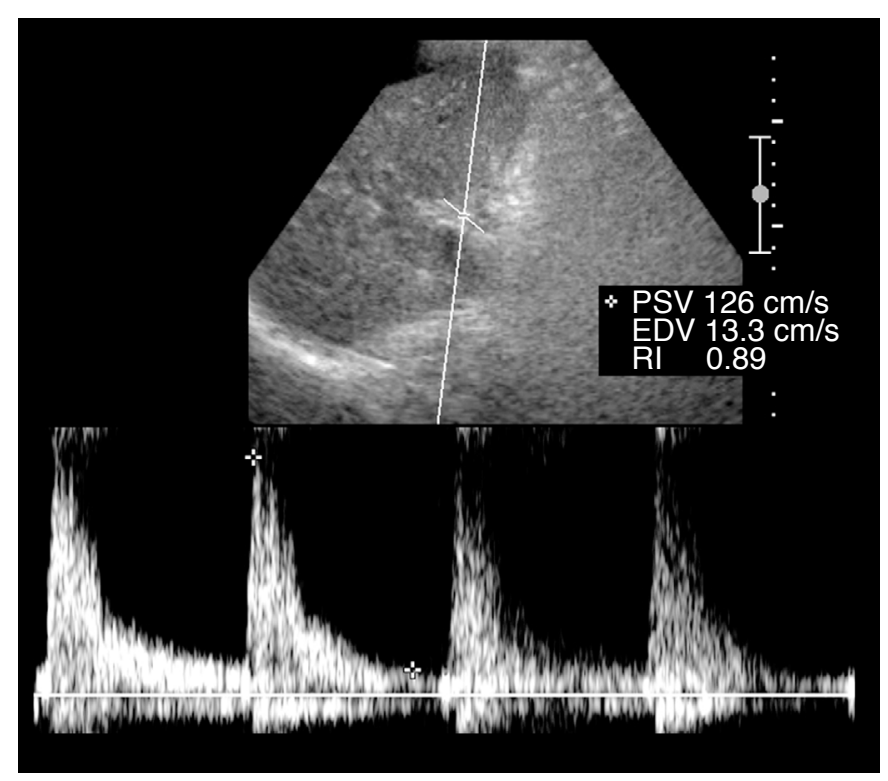

C

\section{CEUS for Monitoring Tumor Treatment}

CEUS can be used to monitor FLL treatment, for treatment guidance in the pre-treatment evaluation of the ablation target, as well as in the peri-procedural assessment of treatment results $[57,58]$. The pre-treatment evaluation includes an assessment of ablation target size, vascularization, and tumor margins. CEUS fusion imaging, CEUS-guided technology, and the possibility of real-time assessment are of pivotal importance in the ablative treatment of undetected or inconspicuous target lesions by unenhanced US [59-62]. CEUS performed 10-15 minutes after ablation treatment

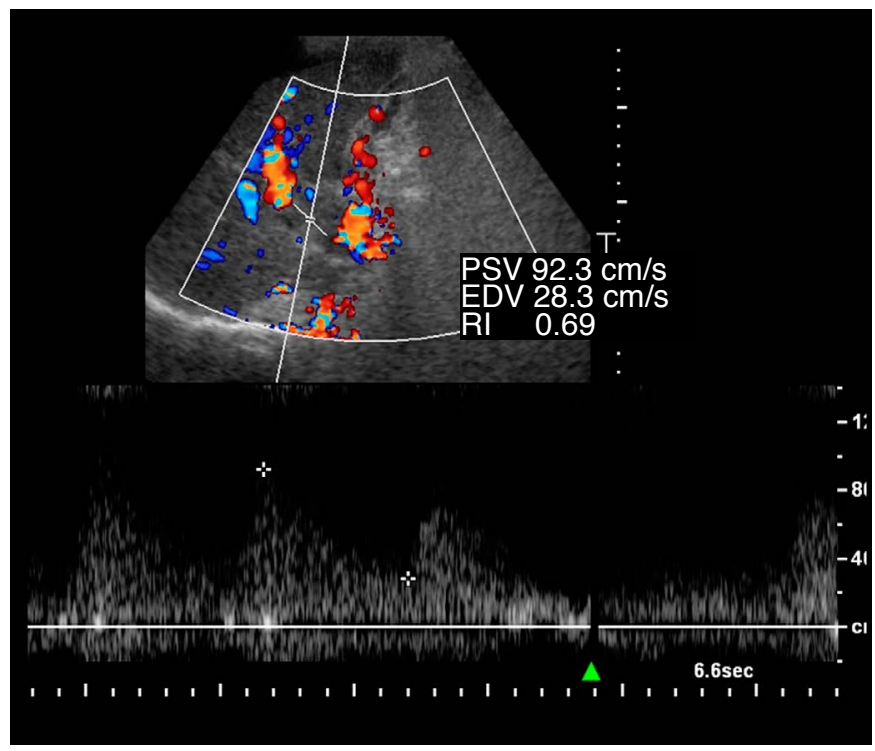

B

Fig. 9. Malignant thrombosis of the portal vein.

A. Pre-contrast spectral Doppler analysis shows only venous pattern (portal) flow in the thrombosed segment of the portal vein. B. After contrast-enhanced ultrasonography, the spectral Doppler analysis shows intra-thrombus arterial flow. Microbubble agents render intra-thrombus blood flow more evident in both spectral and color Doppler modes. C. It is possible to observe a flow pattern in the common hepatic artery. Note that the pattern seen in the hepatic artery is quite different (high resistivity) from that of the tumoral thrombus (lower resistivity). When we find arterial flow in a vein, we can close the diagnosis of tumor thrombosis or "tumor in vein." PSV, peak systolic velocity; EDV, end-diastolic velocity; RI, resistive index.

enables an evaluation of therapeutic efficacy and detection of any viable residual tumor, which allows instantaneous CEUS-guided re-ablation as part of the same procedure if required. Therefore, CEUS is a reliable method of evaluating the ablation margin and detecting tumor recurrence, potentially reducing the number of CT examinations needed during follow-up. Regular CEUS followup weeks to months after ablation can detect local recurrence and new lesions (Figs. 11, 12). In the early post-ablation evaluation (within the first 30 days), a thin, uniform, and enhanced hyperemic rim is visible along the periphery of the necrotic region, similar to the findings on contrast-enhanced CT. Care must be taken not to 


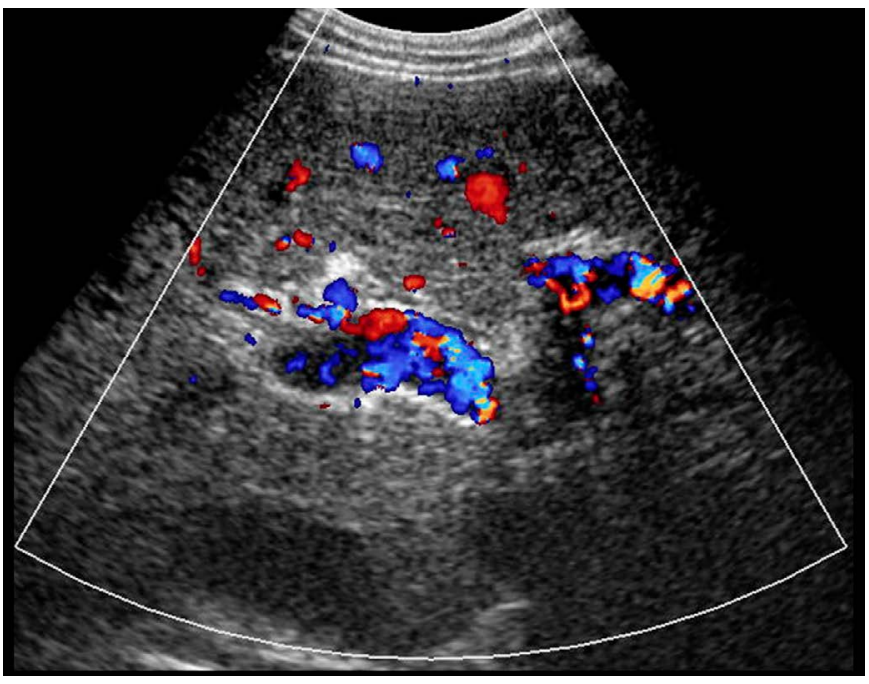

A

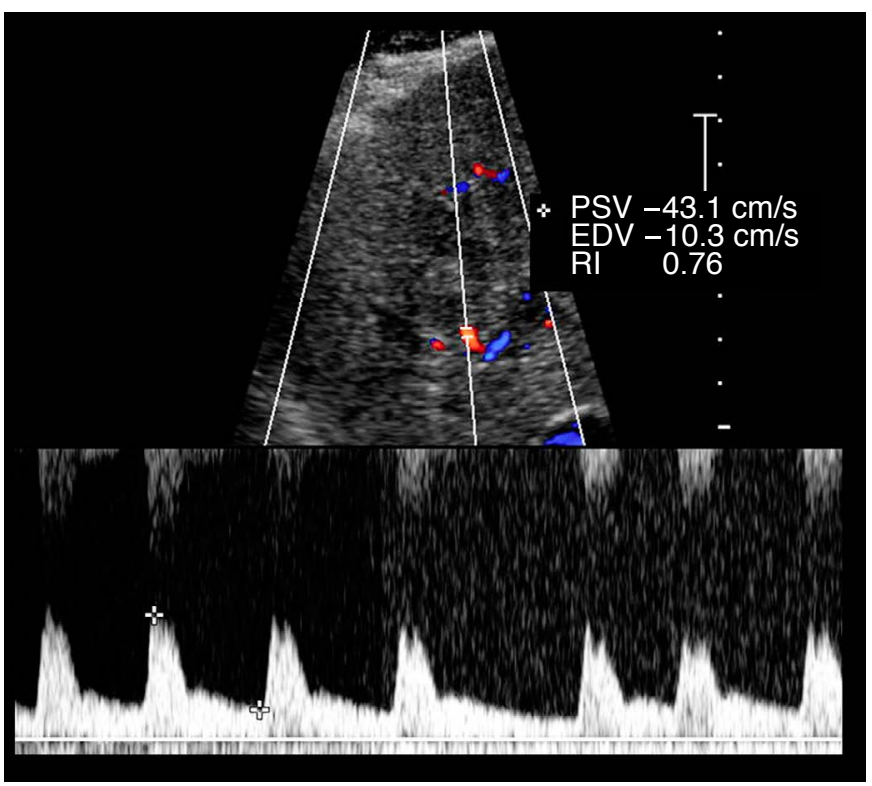

C

confuse this with recurrence.

There are several possibilities of treatment, alone or in combination, that can improve patients' outcomes. These depend on the HCC staging and the clinical conditions of the patient. CEUS can assist in the evaluation of the success of localized treatments, such as chemoembolization and ethanol ablation of the lesion.

\section{Conclusion}

CEUS plays an important role in the diagnosis of FLLs, with well-established standards for malignant liver lesions. The main characteristic is washout in the portal and/or late phases, usually

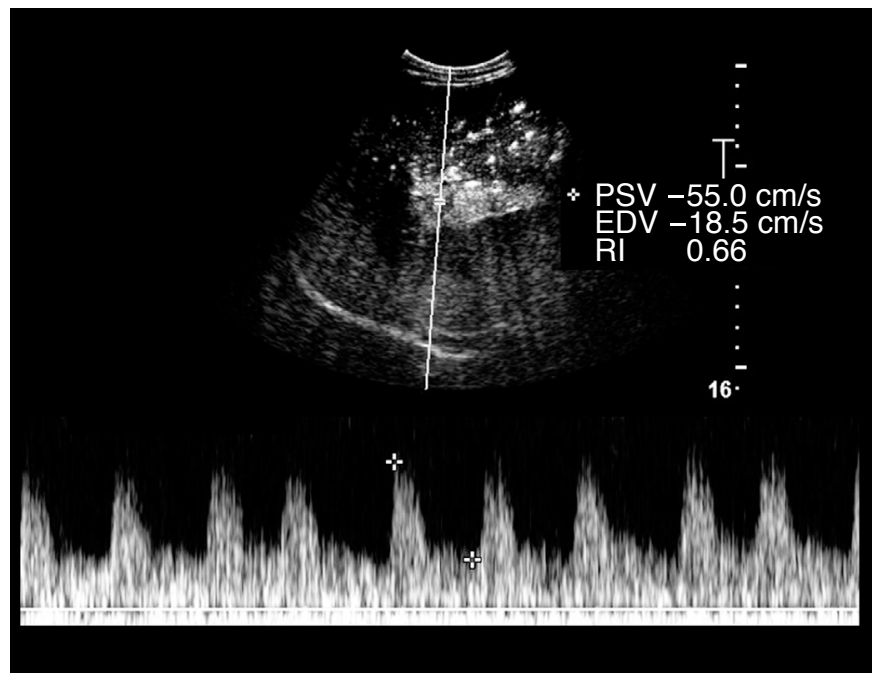

B

Fig. 10. Contrast-enhanced ultrasonography (CEUS) analysis of malignant thrombosis in the portal and hepatic veins.

A, B. Color Doppler indicates that there is vascularization between the partial thrombi of the right portal branch. C. Spectral Doppler demonstrates arterial flow in the thrombus after CEUS. The lower right panel shows arterial flow inside the right hepatic vein after CEUS. PSV, peak systolic velocity; EDV, end-diastolic velocity; RI, resistive index.

preceded by hyperenhancement in the arterial phase. CEUS improves metastasis detection and has good sensitivity and specificity in evaluating malignant lesions, such as HCC, ICC, and malignant PVT.

CEUS has some advantages when compared to $\mathrm{CT}$ and MRI, such as high temporal resolution, virtually no known adverse effects, being ionizing radiation-free, and the possibility of use in patients with impaired renal function, making this method an important alternative when contrast agents of other imaging techniques are contraindicated. It may also be an option for patients who cannot undergo general anesthesia and for patients for whom bedside US is the only feasible option. 


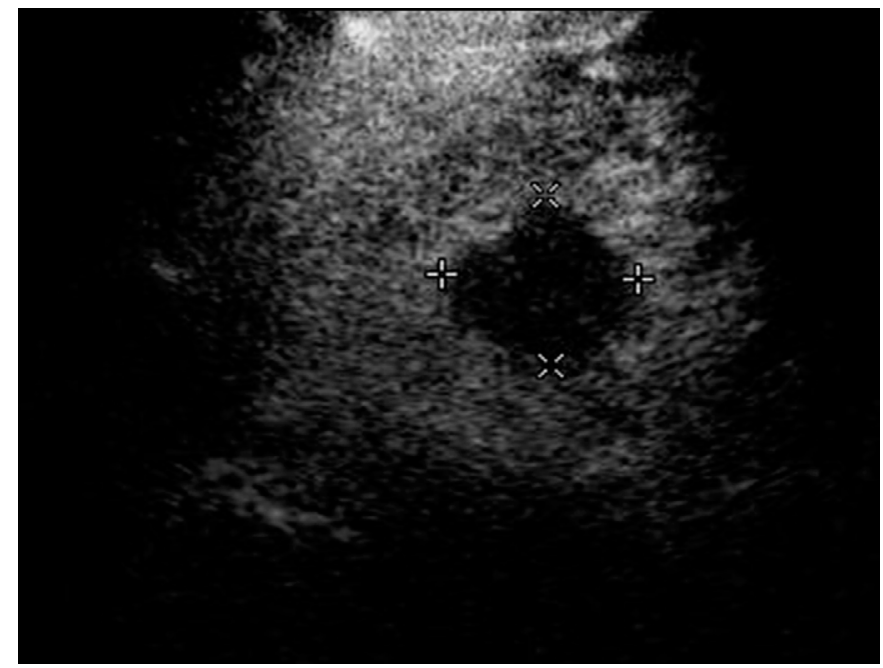

A

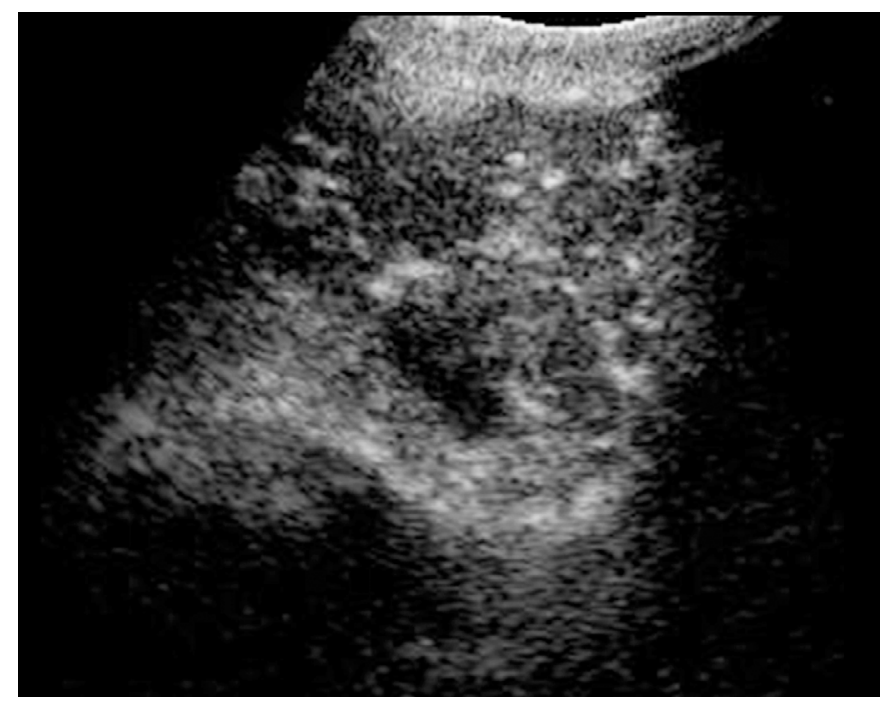

C

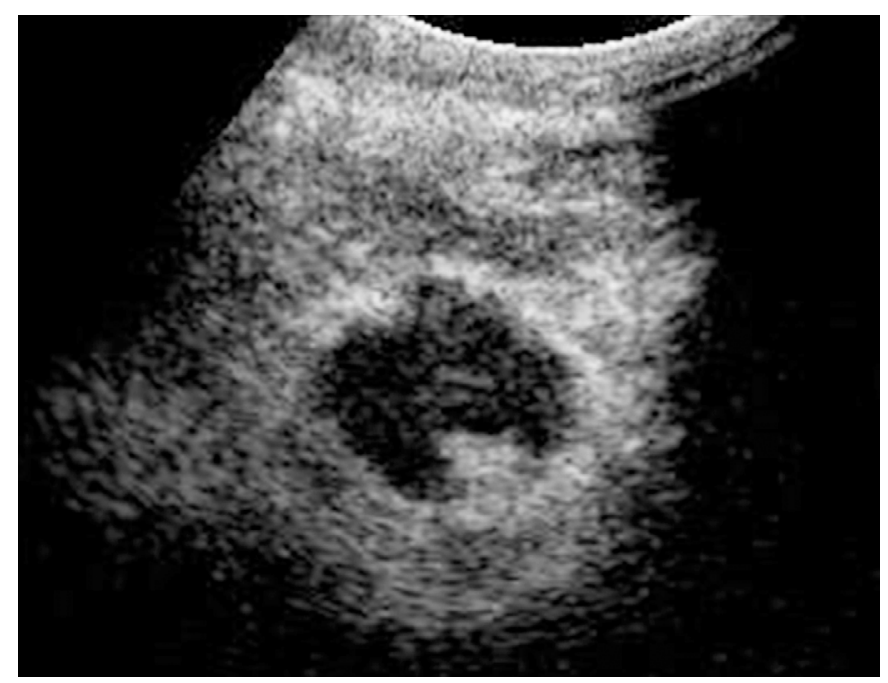

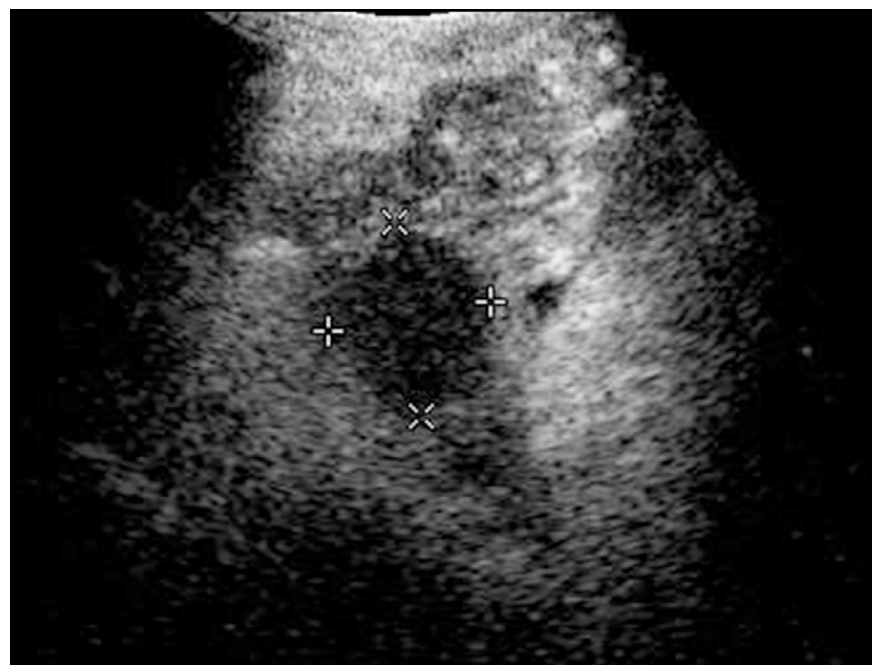

B

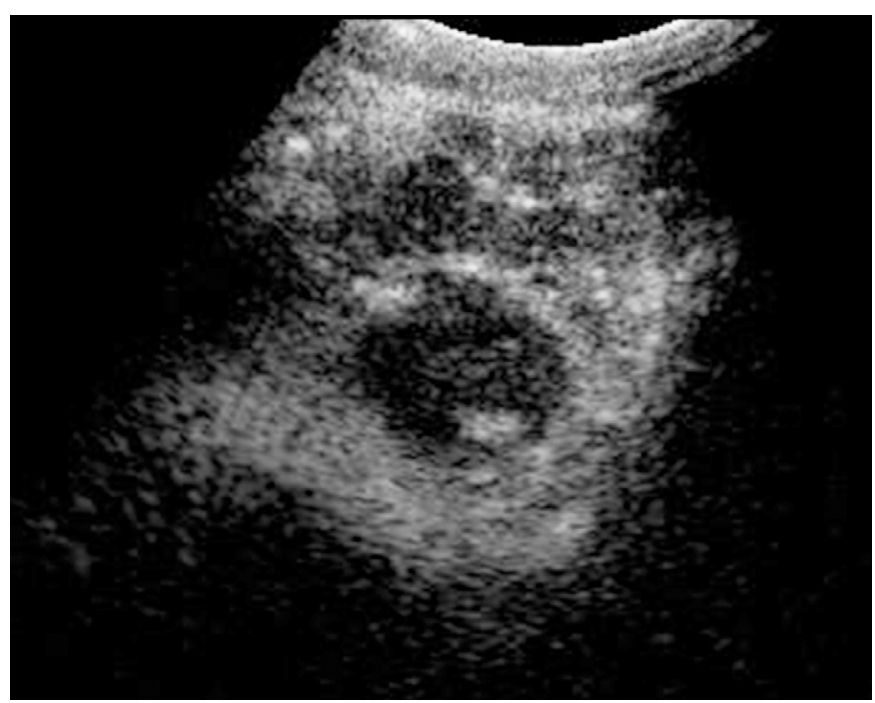

D

Fig. 11. A 65-year-old man, referred for evaluation after chemoembolization.

In B-mode ultrasonography, pre-contrast (A, B), a hypoechoic nodule with irregular borders is observed, measuring about $3.0 \times 2.8 \mathrm{~cm}$. The contrast-enhanced ultrasonography evaluation shows the presence of arterial hyperenhancement in the wall nodule, which starts in the arterial phase $(C, D)$ indicating the presence of viable tumors, most evident in the portal phase (E) within the treated nodule. This indicates the need to complement the treatment with a new ablative procedure. 


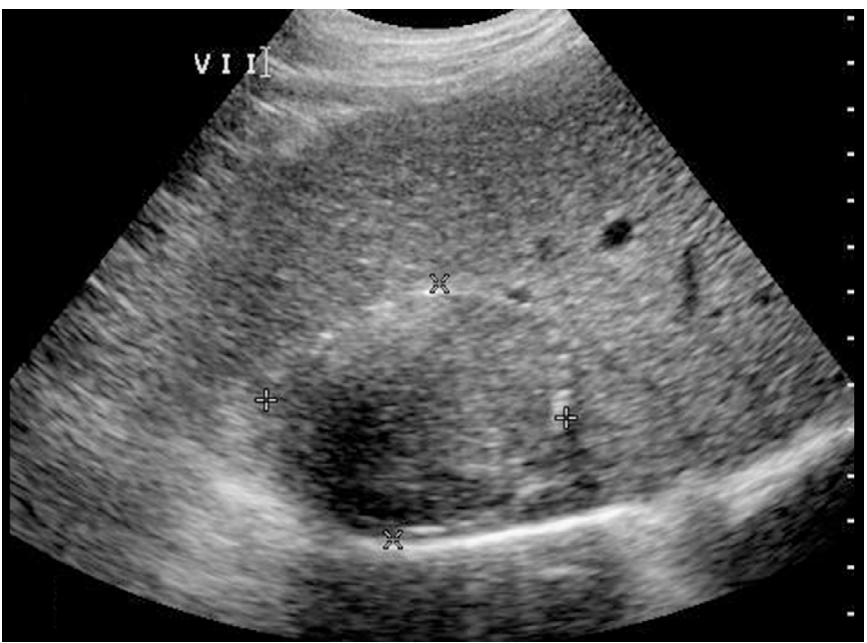

A

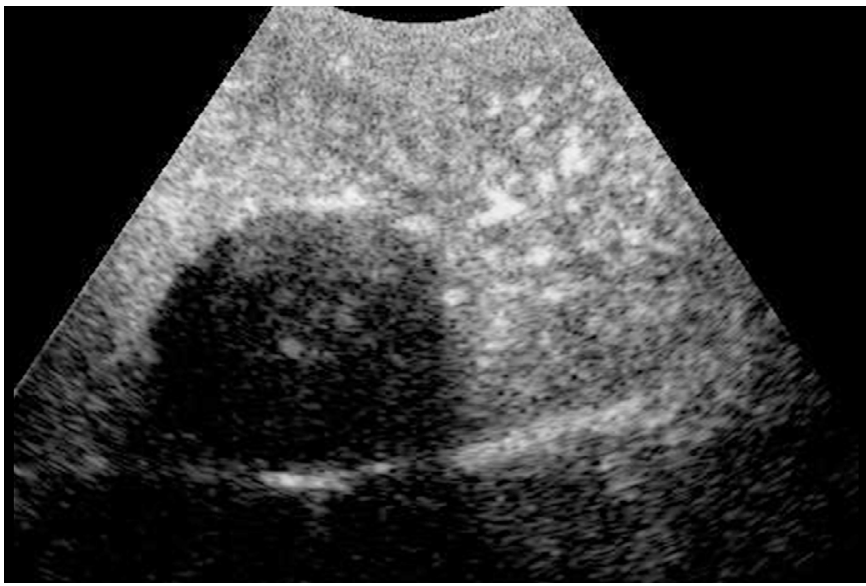

C

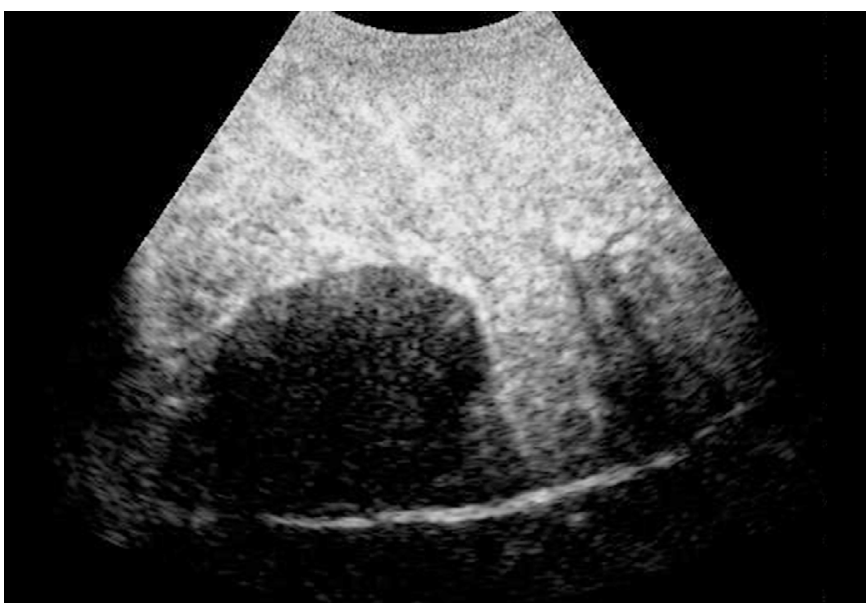

$\mathrm{E}$

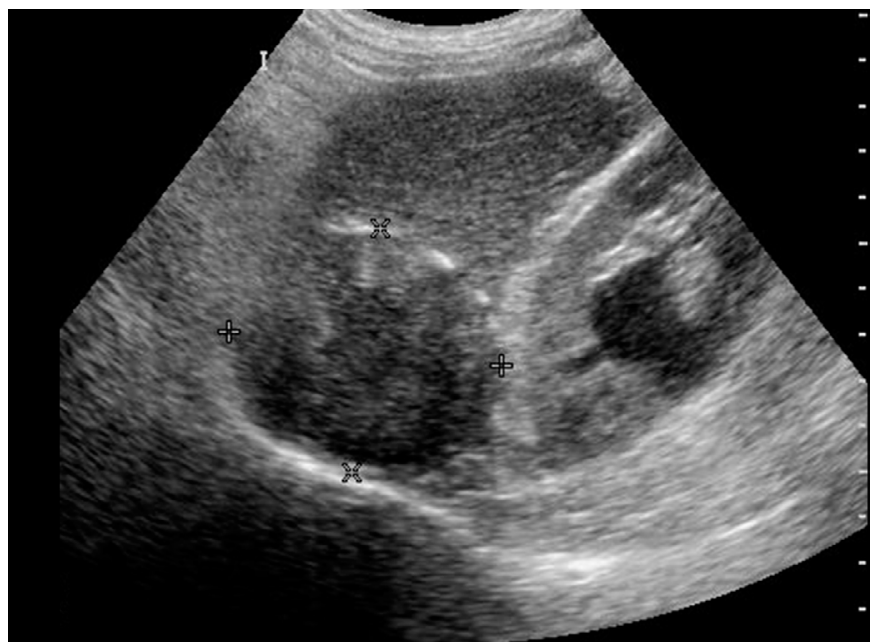

B

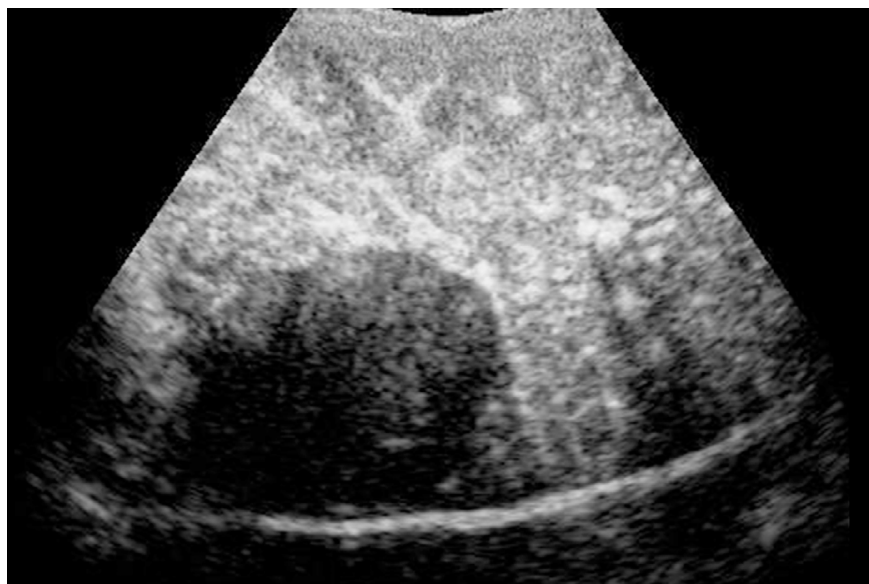

D

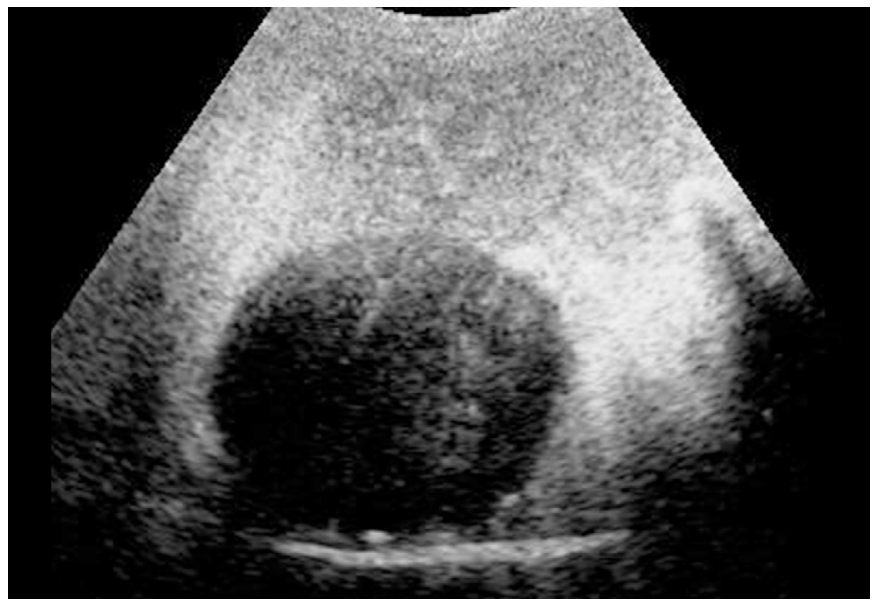

Fig. 12. A 72-year-old man, referred for post-treatment evaluation (three sessions) by chemoembolization.

In pre-contrast B-mode ultrasonography (A, B, two planes), a hypoechoic nodule is observed in segment VI/VII, with regular contours, with dense peripheral spots, measuring about $7.5 \times 5.0 \mathrm{~cm}$. The contrast-enhanced ultrasonography evaluation shows the absence of arterial contrast (C, D), more evident in the portal $(E)$ and late phases (F), indicating the absence of a viable tumor in the treated nodule. This shows that the treatment was successful. 
ORCID: Maria Cristina Chammas: https://orcid.org/0000-0001-7041-3079; André Leopoldino Bordini: https://orcid.org/0000-0002-5789-3853

\section{Author Contributions}

Conceptualization: Chammas MC, Bordini AL. Data acquisition: Chammas MC, Bordini AL. Data analysis or interpretation: Chammas MC, Bordini AL. Drafting of the manuscript: Chammas MC, Bordini AL. Critical revision of the manuscript: Chammas MC. Approval of the final version of the manuscript: all authors.

\section{Conflict of Interest}

No potential conflict of interest relevant to this article was reported.

\section{Acknowledgments}

The authors thank Celine Pompeia for her excellent revision of the manuscript.

\section{References}

1. Dietrich CF, Averkiou M, Nielsen MB, Barr RG, Burns PN, Calliada $F$, et al. How to perform contrast-enhanced ultrasound (CEUS). Ultrasound Int Open 2018;4:E2-E15.

2. Dietrich $C F$, Nolsoe CP, Barr RG, Berzigotti A, Burns PN, Cantisani $V$, et al. Guidelines and good clinical practice recommendations for contrast enhanced ultrasound (CEUS) in the Liver: update 2020 WFUMB in Cooperation with EFSUMB, AFSUMB, AIUM, and FLAUS. Ultraschall Med 2020;41:562-585.

3. Seitz K, Strobel D, Bernatik T, Blank W, Friedrich-Rust M, Herbay A, et al. Contrast-enhanced ultrasound (CEUS) for the characterization of focal liver lesions - prospective comparison in clinical practice: CEUS vs. CT (DEGUM multicenter trial). Parts of this manuscript were presented at the Ultrasound Dreilandertreffen 2008, Davos. Ultraschall Med 2009;30:383-389.

4. Dietrich CF, Kratzer W, Strobe D, Danse E, Fessl R, Bunk A, et al. Assessment of metastatic liver disease in patients with primary extrahepatic tumors by contrast-enhanced sonography versus CT and MRI. World J Gastroenterol 2006;12:1699-1705.

5. Seitz K, Bernatik T, Strobel D, Blank W, Friedrich-Rust M, Strunk H, et al. Contrast-enhanced ultrasound (CEUS) for the characterization of focal liver lesions in clinical practice (DEGUM Multicenter Trial): CEUS vs. MRI: a prospective comparison in 269 patients. Ultraschall Med 2010;31:492-499.

6. Seitz K, Greis C, Schuler A, Bernatik T, Blank W, Dietrich CF, et al. Frequency of tumor entities among liver tumors of unclear etiology initially detected by sonography in the noncirrhotic or cirrhotic livers of 1349 patients: results of the DEGUM multicenter study. Ultraschall Med 2011;32:598-603.

7. Westwood M, Joore M, Grutters J, Redekop K, Armstrong N, Lee
$\mathrm{K}$, et al. Contrast-enhanced ultrasound using SonoVue(R) (sulphur hexafluoride microbubbles) compared with contrast-enhanced computed tomography and contrast-enhanced magnetic resonance imaging for the characterisation of focal liver lesions and detection of liver metastases: a systematic review and cost-effectiveness analysis. Health Technol Assess 2013;17:1-243.

8. Friedrich-Rust M, Klopffleisch T, Nierhoff J, Herrmann E, Vermehren J, Schneider MD, et al. Contrast-enhanced ultrasound for the differentiation of benign and malignant focal liver lesions: a metaanalysis. Liver Int 2013;33:739-755.

9. Albrecht T, Hohmann J, Oldenburg A, Skrok J, Wolf KJ. Detection and characterisation of liver metastases. Eur Radiol 2004;14 Suppl 8:P25-33.

10. Lencioni R, Della Pina C, Crocetti L, Bozzi E, Cioni D. Clinical management of focal liver lesions: the key role of real-time contrast-enhanced US. Eur Radiol 2007;17 Suppl 6:F73-F79.

11. Cantisani V, Grazhdani H, Fioravanti C, Rosignuolo M, Calliada $F$, Messineo $D$, et al. Liver metastases: contrast-enhanced ultrasound compared with computed tomography and magnetic resonance. World J Gastroenterol 2014;20:9998-10007.

12. Solbiati L, Tonolini M, Cova L, Goldberg SN. The role of contrastenhanced ultrasound in the detection of focal liver leasions. Eur Radiol 2001;11 Suppl 3:E15-E26.

13. Cosgrove D, Blomley M. Liver tumors: evaluation with contrastenhanced ultrasound. Abdom Imaging 2004;29:446-454.

14. Sporea I, Sandulescu DL, Sirli R, Popescu A, Danila M, Sparchez $Z$, et al. Contrast-enhanced ultrasound for the characterization of malignant versus benign focal liver lesions in a prospective multicenter experience: the SRUMB study. J Gastrointestin Liver Dis 2019;28:191-196.

15. Sporea I, Badea R, Popescu A, Sparchez Z, Sirli RL, Danila M, et al. Contrast-enhanced ultrasound (CEUS) for the evaluation of focal liver lesions: a prospective multicenter study of its usefulness in clinical practice. Ultraschall Med 2014;35:259-266.

16. American College of Radiology. CEUS LI-RADS v2017 CORE [Internet]. Reston, VA: American College of Radiology, 2017 [cited 2020 Dec 28]. Available from: https://www.acr.org/-/media/ACR/ Files/RADS/LI-RADS/CEUS-LI-RADS-2017-Core.pdf?la=en\%20n.d.

17. Claudon M, Dietrich CF, Choi BI, Cosgrove DO, Kudo M, Nolsoe CP, et al. Guidelines and good clinical practice recommendations for contrast enhanced ultrasound (CEUS) in the liver: update 2012: a WFUMB-EFSUMB initiative in cooperation with representatives of AFSUMB, AIUM, ASUM, FLAUS and ICUS. Ultraschall Med 2013;34:11-29.

18. Dietrich CF, Nolsoe CP, Barr RG, Berzigotti A, Burns PN, Cantisani $V$, et al. Guidelines and good clinical practice recommendations for contrast-enhanced ultrasound (CEUS) in the liver: update 2020 WFUMB in cooperation with EFSUMB, AFSUMB, AIUM, and FLAUS. Ultrasound Med Biol 2020;46:2579-2604. 
19. Trillaud H, Bruel JM, Valette PJ, Vilgrain V, Schmutz G, Oyen R, et al. Characterization of focal liver lesions with SonoVue-enhanced sonography: international multicenter-study in comparison to CT and MRI. World J Gastroenterol 2009;15:3748-3756.

20. Martie A, Bota S, Sporea I, Sirli R, Popescu A, Danila M. The contribution of contrast enhanced ultrasound for the characterization of benign liver lesions in clinical practice: a monocentric experience. Med Ultrason 2012;14:283-287.

21. Guang Y, Xie L, Ding H, Cai A, Huang Y. Diagnosis value of focal liver lesions with SonoVue(R)-enhanced ultrasound compared with contrast-enhanced computed tomography and contrast-enhanced MRI: a meta-analysis. J Cancer Res Clin Oncol 2011;137:15951605.

22. Karhunen PJ. Benign hepatic tumours and tumour like conditions in men. J Clin Pathol 1986;39:183-188.

23. Sandrose SW, Karstrup S, Gerke O, Rafaelsen S. Contrast enhanced ultrasound in CT-undetermined focal liver lesions. Ultrasound Int Open 2016;2:E129-E135.

24. Volk M, Strotzer M, Lenhart M, Techert J, Seitz J, Feuerbach S. Frequency of benign hepatic lesions incidentally detected with contrast-enhanced thin-section portal venous phase spiral CT. Acta Radiol 2001;42:172-175.

25. von Herbay A, Westendorff J, Gregor M. Contrast-enhanced ultrasound with SonoVue: differentiation between benign and malignant focal liver lesions in 317 patients. J Clin Ultrasound 2010;38:1-9.

26. Strobel D, Seitz K, Blank W, Schuler A, Dietrich C, von Herbay A, et al. Contrast-enhanced ultrasound for the characterization of focal liver lesions: diagnostic accuracy in clinical practice (DEGUM multicenter trial). Ultraschall Med 2008;29:499-505.

27. Strobel D, Seitz K, Blank W, Schuler A, Dietrich CF, von Herbay A, et al. Tumor-specific vascularization pattern of liver metastasis, hepatocellular carcinoma, hemangioma and focal nodular hyperplasia in the differential diagnosis of 1,349 liver lesions in contrast-enhanced ultrasound (CEUS). Ultraschall Med 2009;30:376-382.

28. Strobel D, Bernatik T, Blank W, Schuler A, Greis C, Dietrich CF, et al. Diagnostic accuracy of CEUS in the differential diagnosis of small $(\leq 20 \mathrm{~mm})$ and subcentimetric $(\leq 10 \mathrm{~mm})$ focal liver lesions in comparison with histology. Results of the DEGUM multicenter trial. Ultraschall Med 2011;32:593-597.

29. Bernatik T, Seitz K, Blank W, Schuler A, Dietrich CF, Strobel D. Unclear focal liver lesions in contrast-enhanced ultrasonography: lessons to be learned from the DEGUM multicenter study for the characterization of liver tumors. Ultraschall Med 2010;31:577-581.

30. Dietrich CF, Ignee A, Trojan J, Fellbaum C, Schuessler G. Improved characterisation of histologically proven liver tumours by contrast enhanced ultrasonography during the portal venous and specific late phase of SHU 508A. Gut 2004;53:401-405.
31. Sporea I, Badea R, Martie A, Dumitru E, loanitescu S, Sirli R, et al. Contrast enhanced ultrasound for the evaluation of focal liver lesions in daily practice: a multicentre study. Med Ultrason 2012;14:95-100.

32. Devine AS, Jackson CS, Lyons L, Mason JD. Frequency of incidental findings on computed tomography of trauma patients. West J Emerg Med 2010;11:24-27.

33. Bartolotta TV, Sandonato L, Taibbi A, Latteri S, Soresi M, Lombardo $G$, et al. Focal liver lesions: clinical usefulness of contrastenhanced ultrasound in the selection of surgical patients. Chir Ital 2009;61:295-307.

34. Wang JY, Feng SY, Xu JW, Li J, Chu L, Cui XW, et al. Usefulness of the contrast-enhanced ultrasound liver imaging reporting and data system in diagnosing focal liver lesions by inexperienced radiologists. J Ultrasound Med 2020;39:1537-1546.

35. Claudon M, Dietrich CF, Choi BI, Cosgrove DO, Kudo M, Nolsoe CP, et al. Guidelines and good clinical practice recommendations for contrast enhanced ultrasound (CEUS) in the liver: update 2012: a WFUMB-EFSUMB initiative in cooperation with representatives of AFSUMB, AIUM, ASUM, FLAUS and ICUS. Ultrasound Med Biol 2013;39:187-210.

36. Rodgers SK, Fetzer DT, Gabriel H, Seow JH, Choi HH, Maturen KE, et al. Role of US LI-RADS in the LI-RADS Algorithm. Radiographics 2019;39:690-708.

37. Kono Y, Sirlin CB, Fetzer DT, Kim TK, Rodgers SK, Piscaglia F, et al. Time to clarify common misconceptions about the Liver Imaging Reporting and Data System for contrast-enhanced US. Radiology 2020;295:245-247.

38. Lyshchik A, Kono Y, Dietrich CF, Jang HJ, Kim TK, Piscaglia F, et al. Contrast-enhanced ultrasound of the liver: technical and lexicon recommendations from the ACR CEUS LI-RADS working group. Abdom Radiol (NY) 2018;43:861-879.

39. Dietrich CF, Potthoff $A$, Helmberger $T$, Ignee A, Willmann JK; CEUS LI-RADS Working Group. Contrast-enhanced ultrasound: Liver Imaging Reporting and Data System (CEUS LI-RADS). Z Gastroenterol 2018;56:499-506.

40. Terzi E, lavarone M, Pompili M, Veronese L, Cabibbo G, Fraquelli M, et al. Contrast ultrasound LI-RADS LR-5 identifies hepatocellular carcinoma in cirrhosis in a multicenter restropective study of 1,006 nodules. J Hepatol 2018;68:485-492.

41. Forner A, Vilana R, Ayuso C, Bianchi L, Sole M, Ayuso JR, et al. Diagnosis of hepatic nodules $20 \mathrm{~mm}$ or smaller in cirrhosis: prospective validation of the noninvasive diagnostic criteria for hepatocellular carcinoma. Hepatology 2008;47:97-104.

42. Leoni S, Piscaglia F, Golfieri R, Camaggi V, Vidili G, Pini P, et al. The impact of vascular and nonvascular findings on the noninvasive diagnosis of small hepatocellular carcinoma based on the EASL and AASLD criteria. Am J Gastroenterol 2010;105:599-609.

43. Boozari B, Soudah B, Rifai K, Schneidewind S, Vogel A, Hecker H, 
et al. Grading of hypervascular hepatocellular carcinoma using late phase of contrast enhanced sonography: a prospective study. Dig Liver Dis 2011;43:484-490.

44. Fan ZH, Chen MH, Dai Y, Wang YB, Yan K, Wu W, et al. Evaluation of primary malignancies of the liver using contrast-enhanced sonography: correlation with pathology. AJR Am J Roentgenol 2006;186:1512-1519.

45. lavarone M, Sangiovanni A, Forzenigo LV, Massironi S, Fraquelli $\mathrm{M}$, Aghemo A, et al. Diagnosis of hepatocellular carcinoma in cirrhosis by dynamic contrast imaging: the importance of tumor cell differentiation. Hepatology 2010;52:1723-1730.

46. Jang HJ, Kim TK, Burns PN, Wilson SR. Enhancement patterns of hepatocellular carcinoma at contrast-enhanced US: comparison with histologic differentiation. Radiology 2007;244:898-906.

47. Chen MH, Dai Y, Yan K, Fan ZH, Yin SS, Yang W, et al. The role of contrast-enhanced ultrasound on the diagnosis of small hepatocellular carcinoma $(\leq 3 \mathrm{~cm})$ in patients with cirrhosis. Hepatol Res 2006;35:281-288.

48. Little JM, Richardson A, Tait N. Hepatic dystychoma: a five year experience. HPB Surg 1991;4:291-297.

49. Rossi S, Ghittoni G, Ravetta V, Torello Viera F, Rosa L, Serassi M, et al. Contrast-enhanced ultrasonography and spiral computed tomography in the detection and characterization of portal vein thrombosis complicating hepatocellular carcinoma. Eur Radiol 2008;18:1749-1756.

50. Tarantino L, Francica G, Sordelli I, Esposito F, Giorgio A, Sorrentino $\mathrm{P}$, et al. Diagnosis of benign and malignant portal vein thrombosis in cirrhotic patients with hepatocellular carcinoma: color Doppler US, contrast-enhanced US, and fine-needle biopsy. Abdom Imaging 2006;31:537-544.

51. Chammas MC, Oliveira AC, MJ DA, Moraes PH, Takahashi MS. Characterization of malignant portal vein thrombosis with contrastenhanced ultrasonography. Ultrasound Med Biol 2019;45:50-55.

52. Raza SA, Jang HJ, Kim TK. Differentiating malignant from benign thrombosis in hepatocellular carcinoma: contrast-enhanced ultrasound. Abdom Imaging 2014;39:153-161.

53. Danila M, Sporea I, Popescu A, Sirli R, Sendroiu M. The value of contrast enhanced ultrasound in the evaluation of the nature of portal vein thrombosis. Med Ultrason 2011;13:102-107.
54. Song ZZ, Huang M, Jiang TA, Zhao QY, Yao L, Mou Y, et al. Diagnosis of portal vein thrombosis discontinued with liver tumors in patients with liver cirrhosis and tumors by contrast-enhanced US: a pilot study. Eur J Radiol 2010;75:185-188.

55. Ueno N, Kawamura H, Takahashi H, Fujisawa N, Yoneda M, Kirikoshi $\mathrm{H}$, et al. Characterization of portal vein thrombus with the use of contrast-enhanced sonography. J Ultrasound Med 2006;25:11471152.

56. Rossi S, Rosa L, Ravetta V, Cascina A, Quaretti P, Azzaretti A, et al. Contrast-enhanced versus conventional and color Doppler sonography for the detection of thrombosis of the portal and hepatic venous systems. AJR Am J Roentgenol 2006;186:763-773.

57. Lorentzen T, Nolsoe CP, Ewertsen C, Nielsen MB, Leen E, Havre RF, et al. EFSUMB guidelines on interventional ultrasound (INVUS), Part I. General aspects (short version). Ultraschall Med 2015;36:464472.

58. Nolsoe $C P$, Nolsoe $A B$, Klubien J, Pommergaard $H C$, Rosenberg J, Meloni MF, et al. Use of ultrasound contrast agents in relation to percutaneous interventional procedures: a systematic review and pictorial essay. J Ultrasound Med 2018;37:1305-1324.

59. Park HS, Kim YJ, Yu MH, Jung SI, Jeon HJ. Real-time contrastenhanced sonographically guided biopsy or radiofrequency ablation of focal liver lesions using perflurobutane microbubbles (sonazoid): value of Kupffer-phase imaging. J Ultrasound Med 2015;34:411421.

60. Francica G, Meloni MF, Riccardi L, de Sio I, Terracciano F, Caturelli $E$, et al. Ablation treatment of primary and secondary liver tumors under contrast-enhanced ultrasound guidance in field practice of interventional ultrasound centers: a multicenter study. Eur J Radiol 2018;105:96-101.

61. Liu F, Yu X, Liang P, Cheng Z, Han Z, Dong B. Contrast-enhanced ultrasound-guided microwave ablation for hepatocellular carcinoma inconspicuous on conventional ultrasound. Int I Hyperthermia 2011;27:555-562.

62. Bo XW, Xu HX, Wang D, Guo LH, Sun LP, Li XL, et al. Fusion imaging of contrast-enhanced ultrasound and contrast-enhanced $\mathrm{CT}$ or MRI before radiofrequency ablation for liver cancers. Br J Radiol 2016;89:20160379. 